\title{
Estructura sectorial del empleo, nivel educativo de la fuerza de trabajo y diferenciales de ingresos laborales en la argentina (1992-2014) ${ }^{1}$
}

\author{
Agustín Salvia²; Ramiro Enrique Robles 3 ; María Noel Fachal ${ }^{4}$
}

Recibido: 14 de abril de 2016 / Aceptado: 06 de julio de 2017

Resumen. Algunos estudios sobre los cambios distributivos en la Argentina durante las últimas décadas enfatizan la importancia de la reducción de los premios a la educación en la mejora distributiva. Otros estudios se centran en los cambios en las políticas laborales, y sus efectos sobre las tasas de afiliación a la seguridad social. Menos conocidos son los esfuerzos dedicados a analizar las desigualdades asociadas a la heterogeneidad estructural presente en los mercados laborales periféricos. Retomando esta última perspectiva, se relativizan las diferentes tesis en debate, en particular, el papel de los retornos a la educación vis a vis la desigual inserción sectorial de la fuerza de trabajo. Esta relación se analiza en tres períodos diferentes: a) la etapa de implementación de políticas "ortodoxas" de liberalización económica (1992-1998); b) la fase final y crítica de ese modelo (1998-2003); y c) la etapa dominada por políticas "heterodoxas" orientadas al mercado interno (2003-2014).

Palabras clave: Ingresos laborales; retornos a la educación; heterogeneidad estructural; desigualdad distributiva; Argentina.

\section{[en] Sectoral structure of employment, educational level of labor force and labor income differentials in argentina (1992-2014)}

\begin{abstract}
Some studies about distributive changes during the last decade for Argentina focus on the importance of the reduction of educational awards as a cause of this improvement. Other works emphasize the changes in labor policies, and their effects on the social security affiliation rates. Less known are the efforts dedicated to analyze the inequities associated with the structural heterogeneity present on labor markets within peripheral economies. Resuming this last perspective, the different thesis currently debated are relativized on the role of the educational returns in relation to the unequal insertion in each productive sector. This relation is analyzed through three different periods. a) a phase of implementa-
\end{abstract}

El presente artículo se desarrolló en el marco de las investigaciones coordinadas que llevan adelante el Observatorio de la Deuda Social Argentina de la Universidad Católica Argentina (ODSA-UCA) y el programa Cambio Estructural y Desigualdad Social con sede en el Instituto de Investigaciones Gino Germani de la Universidad de Buenos Aires (IIGG-UBA). En ambos casos, sedes regionales del proyecto International Network for Comparative Analysis of Social Inequalities, en el marco del programa "Horizonte 2020" de la Unión Europea, bajo la coordinación del investigador principal Dr. Pedro López Rodán. Los autores agradecen al Lic. Santiago Poy su contribución en la elaboración de las bases de datos utilizadas en este estudio.

2 Investigador Principal CONICET, Director de investigación del Observatorio de la Deuda Social Argentina de la Universidad Católica (ODSA-UCA). agsalvia@retina.ar

3 Universidad de Buenos Aires. Auxiliar de Investigación del programa Cambio Estructural y Desigualdad en el Instituto Gino Germani (IIGG-UBA). ramirorobles91@gmail.com

4 Universidad de Buenos Aires. Becaria de doctorado del CONICET del programa Cambio Estructural y Desigualdad con sede en el Instituto de Investigaciones Gino Germani (IIGG-UBA). mnoelfachal@gmail.com 
tion of "orthodox" liberal policies (1992-1998); b) the final phase and crisis of this model (1998-2003); c) a phase dominated by "heterodox" policies oriented to the local market (2003-2014).

Keywords: Labor income; returns to education; structural heterogeneity; distributive inequality; Argentina.

Sumario: 1. Introducción. 2. Debate teórico ¿capital humano, políticas laborales o desigualdades estructurales? 3. Cambios en el nivel educativo de los ocupados durante el periodo 1992-2014. 4. Premios en los ingresos según nivel educativo y sector de inserción ocupacional. 5. Análisis de elasticidades en los ingresos laborales horarios según nivel educativo y sector de inserción. 6. Comentarios finales. 7. Referencias bibliográficas.

Cómo citar: Salvia, A.; Robles, R. E.; Fachal; M. N. (2018) "Estructura sectorial del empleo, nivel educativo de la fuerza de trabajo y diferenciales de ingresos laborales en la argentina (1992-2014)". Cuadernos de Relaciones Laborales, 36(2), 325-324.

\section{Introducción}

A poco de comenzar el siglo XXI, la Argentina inició un proceso de reducción de la desigualdad en la distribución del ingreso que contrastó con el aumento que tuvo lugar durante la década de los años noventa (Beccaria y Maurizio, 2012; Gasparini, Galiani, Cruces, y Acosta, 2011; Salvia y Vera, 2013; Trujillo y Villafañe, 2011). La literatura coincide en atribuir a las remuneraciones laborales un papel central en estos procesos. La dinámica de este proceso se asocia en general a las cambiantes políticas económicas, sociales y laborales que atravesaron al país durante el último cuarto de siglo. En primer lugar, un período signado por la implementación de políticas de estabilización, apertura comercial y liberalización económica (1992-2001); y, en segundo lugar, luego de la crisis 2001-2002, una etapa de recuperación y crecimiento bajo políticas heterodoxas orientadas al mercado interno (2001-2015). Estas políticas impactaron de manera diferente sobre la estructura productiva, el funcionamiento del mercado de trabajo y la configuración de la estructura ocupacional.

En este marco, una parte de los estudios sobre los cambios en la desigualdad de los ingresos laborales enfatiza la importancia del mercado laboral como protagonista central de este proceso. Se argumenta, por ejemplo, que el aumento de la desigualdad registrada durante la década anterior y su posterior reducción después de la crisis 2001-2003, se explicarían, mayormente, por un crecimiento primero y una baja después de los premios a la educación superior, siendo esto resultado de ajustes en la oferta y demanda de calificaciones, en contexto en donde el crecimiento económico experimentó un salto tecnológico (Gasparini et al., 2011; Gasparini y Lustig, 2011; Cornia y Martorano, 2012). Desde otra perspectiva, algunos estudios priorizan el efecto de las políticas económicas, laborales y de ingresos sobre la demanda de empleo, las tasas de registración de trabajadores afiliados a la seguridad social y la fijación de remuneraciones, dependiendo esto último del protagonismo ejercido por instituciones como la negociación colectiva o el salario mínimo. En los años noventa el deterioro social habría estado asociado a las políticas de apertura comercial, privatización de empresas públicas, flexibilización laboral y desregulación económica, 
con efectos regresivos sobre el mercado interno; mientras que el mercado laboral habría recuperado progresividad a partir de 2003, en el marco de un fuerte crecimiento del empleo, caída en los niveles de "informalidad" laboral ${ }^{5}$ y ejercicio de políticas activas en materia salarial (Beccaria y Maurizio, 2012; Beccaria, Maurizio y Vázquez, 2015).

Por último, no menos importantes han sido los esfuerzos dedicados a dar cuenta de los cambios y las continuidades en la distribución del ingreso laboral como efecto de la heterogeneidad estructural entre sectores formales e informales que atraviesa al mercado laboral (Prebisch, 1949; PREALC-OIT, 1978; CEPAL, 2012). Desde esta perspectiva se afirma que el aumento de la desigualdad laboral durante el período neoliberal se habría debido tanto a una mayor participación en los ingresos laborales por parte de los trabajadores de las unidades económicas más dinámicas, incluido el sector público "modernizado", como a una retracción en la participación de las remuneraciones generadas en las microunidades económicas informales. Una vez pasada la crisis e iniciada la rápida reactivación productiva, la caída de la desigualdad habría partido de una dinámica más compleja: menor concentración relativa de ingresos en el segmento de profesionales independientes, así como en las microunidades informales de empleo asalariado y no asalariado; esto a pesar de que los ingresos derivados del sector público y de unidades económicas formales aumentaron su concentración, compensando esto con una menor desigualdad interna (Salvia, 2012; Salvia y Vera, 2013). En consecuencia, el bienestar general habría aumentado pero la heterogeneidad estructural, medida en términos de brechas de ingresos entre sectores se habría mantenido casi inalterada (Salvia y Vera, 2013; Salvia, Vera, y Poy, 2015).

Retomando esta perspectiva, se revisa el papel jugado por oferta y demanda de calificaciones educativas en el mercado de trabajo como explicación de los cambios en la distribución de las remuneraciones durante el período 1992-2014. En tal sentido, cabe preguntarse, ¿cuál fue el comportamiento de los ingresos laborales horarios según el nivel educativo de la fuerza de trabajo, pero también según el tipo de unidad económica de inserción laboral? ¿En qué medida la coexistencia de divergentes segmentos ocupacionales al interior de la estructura productiva y el mercado de trabajo resulta relevante para explicar la relación entre educación, precariedad laboral e ingresos horarios durante las últimas décadas? A estas preguntas subyace la hipótesis de que un factor clave que explicaría los cambios en los niveles de remuneración laboral son las desigualdades productivas entre sectores económico-ocupacionales.

Para responder a las preguntas formuladas, el trabajo examina los cambios experimentados durante el período 1992-2014 en el modo en que correlacionaron los niveles educativos y los ingresos laborales horarios de la población ocupada. En función de testear la hipótesis propuesta, se evalúa el papel del sector de inserción económico-ocupacional en dicha relación a lo largo del tiempo. ${ }^{6}$ Con el objetivo de

El enfoque legal califica de "informal" al empleo asalariado no registrado, al cual en general se lo identifica cuando el empleador no efectúa en beneficio del trabajador los descuentos jubilatorios establecidos por ley. Cabe aclarar que, tal como se amplía más adelante, en este trabajo se adopta una caracterización sectorial de informalidad diferente a la mencionada.

6 Con el fin de aproximar una clasificación operativa sectorial a las distintas formas de inserción laboral, siguiendo la tradición PREALC-OIT (1978) y trabajos anteriores (Salvia et al., 2008; Salvia, 2012), el sector privado formal se compone de patrones, obreros o empleados de establecimientos con más de 5 ocupados y de trabaja- 
otorgar mayor robustez a los resultados se utilizan pruebas de regresión con el fin de estimar las brechas entre sectores ocupacionales y niveles educativos en las tasas de retorno en los ingresos laborales. En tanto que los fenómenos objeto de estudio se desarrollaron durante contextos macroeconómicos diferentes, el análisis se segmentó en tres fases político-económicas: i) el período 1992-1998, como expresión de la etapa caracterizada por reformas de apertura y liberalización económica, ii) el período 1998-2003, en donde dicho modelo experimenta crecientes desajustes financieros y posteriormente una crisis económica, política y social terminal en 20012002; y, iii) el período 2003-2014, un ciclo largo de crecimiento a través de la puesta en práctica de "políticas heterodoxas", fundamentalmente orientadas a proteger el mercado interno y reactivar la capacidad reguladora del Estado (Damill, Frenkel y Rapetti, 2015).

Para cada período se examinan los cambios en los ingresos laborales horarios de la ocupación principal neto de obligaciones fiscales (para el caso de los asalariados), dividiendo para ello el ingreso corriente "de bolsillo", por la cantidad de horas trabajadas durante el mismo período ${ }^{7}$. Con el fin de no perder casos y neutralizar el sesgo generado por los niveles variables de "no respuesta" a las preguntas de ingresos, se procedió a su estimación para cada año y tipo de fuente laboral (Salvia y Donza, 1999; Donza, 2015) ${ }^{8}$. La evidencia empírica se extrajo de los microdatos de la Encuesta Permanente de Hogares (EPH) del INDEC, correspondientes al área metropolitana del Gran Buenos Aires - conformada por la Ciudad Autónoma de Buenos Aires y 24 municipios ${ }^{9}-$. Los años tomados como ventana para el análisis fueron 1992, 1998, 2003 y 2014; agregándose en algunos apartados años intermedios: 1994, 2001, 2007, 2010 y 2012. Debido a las mejoras metodológicas aplicadas sobre la EPH en 2003, y con el fin de hacer comparables el conjunto de indicadores, se aplicó sobre las variables de estudio una metodología de empalme retrospectivo habilitada por la EPH-INDEC $(2003)^{10}$.

dores autónomos profesionales; el sector público está formado por obreros o empleados ocupados cualquiera sea el nivel o segmento nacional, provincial o municipal del mismo; y el sector microinformal se compone de patrones, obreros o empleados de establecimiento de hasta 5 ocupados, trabajadores por cuenta propia no profesionales y el servicio doméstico a los hogares.

7 Los ingresos laborales fueron puestos a valores constantes (pesos del cuarto trimestre 2014). Los ingresos corrientes de la serie 1992-1994-1998-2001-2003 fueron deflactados según el IPC del INDEC, pero para los años posteriores a 2006 se utilizaron deflactores basados en IPC 7 Provincias y el IPC GB (elaborado por ex técnicos de INDEC). Esta decisión se apoya en la reconocida alteración que sufrió el IPC del INDEC a partir de 2007 (CELS, 2009).

8 El método aplicado para estas estimaciones puede consultarse en Salvia y Donza (1999). No obstante, debe aclararse que, en este caso, esta imputación sólo se llevó adelante para las bases "puntuales" de la EPH (19921998-2003), pero no para las de la modalidad "continua" (2003-2014), dado que ya a partir de 2003 el INDEC ofrecía bases de datos con imputaciones de ingresos no declarados.

9 La serie histórica de ingresos monetarios sólo se puede estimar de manera consistente para el Gran Buenos Aires (Ciudad de Buenos Aires y 24 partidos del Conurbano), en donde vive aproximadamente un tercio de la población total del país. Según datos del Censo de Población del Instituto Nacional de Estadísticas y Censos (INDEC) de 2010, el Gran Buenos Aires ocupa una superficie total de 2590 kilómetros cuadrados y reúne 12,8 millones de habitantes, lo cual representa una concentración cercana al 32\% de la población total del país y produce alrededor del $40 \%$ del PBI nacional.

10 La serie de mediciones "puntuales" realizadas por la EPH en los meses de octubre de 1992-1994-1998-2001 fue ajustada, con el fin de hacerla comparable con las mediciones "continuas" realizadas los cuartos trimestres de 2003-2007-2010-2012-2014, a partir de la muestra de empalme provista para el primer semestre de 2003 por el INDEC (ver Salvia, Comas, Gutiérrez Ageitos, Quartulli, y Stefani, 2008). 


\section{Debate teórico: ¿capital humano, políticas laborales o desigualdades estructurales?}

La influencia de la educación sobre la distribución de los ingresos constituye una discusión todavía vigente. Desde la sociología, la visión tradicional se remonta a las teorías funcionalistas de la estratificación, encarnadas inicialmente en los trabajos de Davis y Moore (1945), replicadas en los análisis sobre movilidad social en la sociedad industrial (Germani, 1963; Lipset y Bendix, 1963). En la perspectiva económica neoclásica la relación entre educación e ingresos es tradicionalmente abordada a partir de la teoría del capital humano (Schultz, 1961; Becker, 1957, 1962; Mincer, 1975). Según este enfoque, la decisión de inversión en capital humano por parte de un individuo es similar a la decisión de una empresa de invertir en una maquinaria. En una economía de mercado, la educación constituye un costo en el presente para obtener un mayor flujo de ingresos en el futuro. Por lo cual, la inversión en capital humano influye en la trayectoria del ciclo de vida de la relación ingreso-edad. La teoría del capital humano asigna a la educación un papel preponderante a la explicación de las desigualdades remunerativas entre los trabajadores.

Más recientemente, desde esta perspectiva se argumenta que en la actual fase de integración de los mercados a nivel mundial, el aumento en los niveles de educación de la fuerza de trabajo tendría un papel clave en los cambios distributivos observados en América Latina (Lustig, Lopez-Calva y Ortiz-Juarez, 2013) Otras trabajos resaltan también la creciente relevancia que tiene la adquisición de mayores titulaciones entre la mano de obra para competir por la absorción de los flujos de inversión y, en consecuencia, acceder a mejores puestos de trabajo (Carlson, 2002; Neira, 2007; Paz, 2007). Según algunos círculos ortodoxos, la liberalización económica en contexto de mercados laborales poco flexibles, conduciría inicialmente a un aumento de la desigualdad entre los salarios de trabajadores calificados y no calificados. Sin embargo, con el tiempo, y cuanto más elásticos sean lo mercados, dicha desigualdad debería retraerse como resultado del aumento creciente que experimentaría la oferta laboral de mayor calificación (Galiani y Sanguinetti, 2003).

Al respecto, los resultados que presentan López-Cava y Lustig (2011) y Lustig, López-Calva y Ortiz-Juárez (2013) para los casos de Argentina, México, Perú y Brasil, países en donde se experimentaron reformas de liberalización económica, apuntan a destacar que la desigualdad en los ingresos laborales, luego de crecer, disminuyó a partir del nuevo milenio como resultado de las variaciones experimentadas por el "premio" por calificación. ¿Cómo explicar el incremento en los rendimientos de la educación con una oferta de mano de obra calificada creciente? Según los autores mencionados, fundamentalmente porque a pesar de existir una oferta creciente, la demanda de mano de obra calificada se habría incrementado a mayor velocidad (Lustig et al., 2011). La reasignación sectorial de la producción y el empleo hacia sectores de mayor capital intensivo, habría operado a favor de una demanda competitiva creciente de mano de obra calificada, sobre todo de los trabajadores con grado universitario.

Con relación al aumento de la desigualdad en los años noventa en la Argentina, Cruces y Gasparini (2009) señalan que si bien el efecto directo de la liberalización económica en la desigualdad salarial habría sido modesto, el efecto indirecto -por su repercusión en inversiones de capital intensivo y la adopción de nuevas tecnologías de producción y organización intensivas en el trabajo calificado- habría sido un fac- 
tor relevante, tanto para sesgar la demanda laboral como para aumentar las brechas salariales por educación. A partir de una mayor demanda de trabajadores calificados, el premio por escolaridad habría crecido de manera significativa. Este efecto generado por el aumento de la demanda habría más que compensado la presión a la baja que, por otra parte, generaba la creciente oferta de fuerza de trabajo con estudios superiores (Gasparini et al., 2011). Estos mismos autores, encuentran que los trabajadores no calificados perdieron terreno tanto en términos de salarios por hora como de horas de trabajo durante los años noventa y que estos cambios tuvieron un papel muy importante en la distribución de los salarios y el ingreso familiar ${ }^{11}$.

Pero en contraste con lo ocurrido en la década de liberación económica, la caída de la desigualdad en los años 2000 habría tenido como contexto una reducción de las brechas de ingreso salarial entre los trabajadores (Lustig et al., 2013; Cornia, 2011). Dos tendencias explicarían esta caída: por una parte, el continuado incremento de la oferta de trabajadores con educación superior, ahora por debajo de la demanda de puestos de mayor calificación, en un contexto de desaceleración del cambio tecnológico; y, en segundo lugar, el aumento en la escolaridad media en la oferta laboral, induciendo a una reducción de la desigualdad por educación, en un contexto en donde el aumento del mercado interno y de las exportaciones de materias primas habrían inducido a aumentar la demanda trabajadores de mediana o baja calificación. De esta manera, el mercado laboral habría generado una caída de las primas laborales de la mano de obra más calificada (Gasparini et al., 2011; Gasparini y Lustig, 2011) ${ }^{12}$.

En Argentina, varios trabajos señalan que los cambios en el nivel educativo de la fuerza trabajo sólo explican una parte de la caída de la desigualdad, y que el argumento centrado en el premio a la educación no es suficiente para comprender el menor y/o mayor bienestar social generado en cada uno de los períodos considerados (Beccaria et al., 2015). Estos priorizan el impacto de los cambios en la demanda agregada de empleo, sus efectos sobre el desempleo y la precariedad laboral, los procesos sociales de segmentación, el papel de los sindicatos y de instituciones como el salario mínimo, las regulaciones vigentes en materia de contratación laboral y las convenciones colectivas de trabajo (Beccaria y Maurizio, 2012; Bertranou y Maurizio, 2011; Trujillo y Villafañe, 2011).

11 Cruces y Gasparini (2009) indican que en este período la economía del país experimentó un fuerte aumento en la intensidad de uso de mano de obra calificada en la mayoría de los sectores de la economía por un cambio tecnológico sesgado en favor del trabajo más calificado. Este avance en términos de la calificación de los trabajadores habría sido particularmente marcado en los sectores de manufactura de baja y de alta tecnología, en el comercio y en la administración pública. Siguiendo esta línea argumental, estos autores hacen suya las conclusiones de Esquivel (2007) respecto a los factores que aumentaron la desigualdad entre los ingresos de los trabajadores calificados y los no calificados, concluyendo que el aumento de la desigualdad durante los años de apertura económica fue resultado principalmente de un incremento en los ingresos de los trabajadores más calificados, más que como efecto de una reducción de los salarios de los no calificados (2011: 189-190), aspecto especialmente destacado por los enfoques teóricos en competencia.

12 Aunque inicialmente el choque tecnológico y la apertura comercial de los años noventa habría tenido un efecto generador de desigualdad, se supone que éste debió haber perdido fuerza con el tiempo. Al respecto, se argumenta que tales procesos necesitan tiempo para que los trabajadores no calificados desplazados sean reasignados dentro de una economía más abierta (Gasparini et al., 2011). En igual sentido, en cuanto a los desajuste entre la oferta y demanda de trabajo calificado, se argumenta que -siguiendo a Bourguignon et al. (2004)- tal resultado es consecuencia del tiempo en que los rendimientos crecientes por escolaridad superior deben ajustarse a una oferta creciente de mano de obra de alta escolaridad, a partir de ese momento dichos rendimientos deberían bajar (Lustig et al., 2011). 
Desde una perspectiva estructuralista, se argumenta que ambos tipos de mecanismos que regulan las remuneraciones se hallan fuertemente afectados en contextos en donde la heterogeneidad estructural atraviesa el funcionamiento del sistema productivo, las relaciones sociales y el mercado de trabajo. Esta describe la coexistencia bajo un mismo sistema socioeconómico de un sector de productividad relativamente próxima a la que permiten las técnicas disponibles a nivel del mercado mundial -en el que se concentran las inversiones y el progreso técnico-, junto a un conjunto de unidades económicas de productividad media con baja capacidad de competencia internacional -pero que participan aunque con menor intensidad del proceso de acumulación y de los cambios tecnológicos-; así como también a una serie de actividades económicas de subsistencia, intensivas en mano de obra, tecnológicamente rezagadas $\mathrm{y}$, por lo tanto, de muy baja productividad. Los patrones de empleo y distribución que se originan a partir de esta estructura heterogénea tienden a ser regresivos (Prebisch, 1949; Pinto, 1968; Rodríguez, 2001) $)^{13}$.

Un dato sobresaliente de estos sistemas sería la incapacidad estructural del sector dinámico e intermedio de absorber a toda la mano de obra, por lo que parte de ella se debe ocupar en actividades de subsistencia. Conforme a este abordaje, los elementos asociados a la demanda de empleo, específicamente las características del tejido productivo, asumen especial relevancia en la explicación de las brechas remunerativas entre unidades económicas y trabajadores ${ }^{14}$.

En este contexto, la estructura productiva heterogénea se reproduce debido a una persistente insuficiencia de demanda laboral por parte de los sectores más dinámicos, lo cual genera escasas posibilidades de inserción en el sector moderno para una proporción significativa de la mano de obra y, bajo la perspectiva de análisis que aquí se propone, da lugar a la emergencia y reproducción en el tiempo del llamado sector informal. Este concepto, elaborado inicialmente por la PREALC-OIT (1978) durante la década del setenta, engloba a un conjunto de actividades y puestos de trabajo caracterizados por: a) su orientación a la subsistencia económica; b) los bajos o nulos niveles de productividad; y c) la existencia de una división del trabajo poco desarrollada. En conjunto, estos elementos contribuirían a la generación y reproducción de puestos laborales insuficientemente remunerados, de fácil acceso, pero marcada inestabilidad, y posible ausencia de adecuación a las regulaciones normativas de la esfera del trabajo (Hussmanns, 2004) ${ }^{15}$.

Cabe preguntarse en qué medida los perfiles educativos y las primas salariales correspondientes no están en realidad condicionadas -cuando no determinadas- por las condiciones tecnológicas, organizativas, productivas e, incluso, comerciales y

13 La tesis de la heterogeneidad estructural fue la base del programa inicial de la Comisión Económica para América Latina y el Caribe (Prebisch, 1949, 1970). Actualmente, CEPAL ha retomado el enfoque como marco interpretativo del persistente subdesarrollo latinoamericano (Cimoli et al., 2006; CEPAL, 2012).

14 Según este enfoque, la coexistencia de sectores económicos caracterizados por niveles de productividad y utilización de tecnología diferentes da lugar a una estructura ocupacional donde los ingresos se determinan según la productividad social del segmento económico-ocupacional de inserción (Pinto, 1976; Ocampo, 2001; Rodríguez, 2001). Ver también Di Filippo y Jadue, 1976; Chena, 2010; Salvia, 2012.

15 La distinción entre sectores corresponde al abordaje de las brechas de productividad en las diferentes unidades económicas donde se generan los ingresos de los trabajadores. El tamaño del establecimiento y la calificación de los no asalariados son utilizados como indicadores "proxy" para la distinción de dichas brechas (PREALC-OIT, 1978; Tokman, 1978). Estas dos dimensiones resultaron significativas a los estudios que realizara la PREALC-OIT en la década del setenta, dado que las mismas permiten identificar diferentes estratos de productividad en los que se inserta la fuerza de trabajo, lo cual es de esperar repercuta en las remuneraciones. 
político laborales, bajo las que operan de manera desigual las unidades productivas en un sistema económico. Según este supuesto, tanto la composición de la demanda como el nivel de las remuneraciones por nivel educativo estarían afectados por los rindes de productividad, costos y/o beneficio que generan tales condiciones ${ }^{16}$.

\section{Cambios en el nivel educativo de los ocupados durante el período 1992-2014}

Un primer análisis obliga a examinar los cambios ocurridos en el perfil educativo de la población ocupada en el área metropolitana del Gran Buenos Aires, a nivel general y para cada sector económico-ocupacional, a lo largo de las tres fases macroeconómicas: 1992-1998, 1998-2003, 2003-2014. Las tablas 1, 2 y 3, brindan información relevante al respecto. En ellas se presentan los máximos niveles de educación alcanzados por los ocupados clasificados en tres categorías: 1) Hasta SI: ocupados sin instrucción, con primaria incompleta o completa y secundaria incompleta; 2) SC-TUI: ocupados con secundaria completa o estudios terciarios o universitarios incompletos; y 3) TUC: ocupados con estudios terciarios o universitarios completos.

La tabla 1 registra los cambios ocurridos en la distribución de la fuerza de trabajo por nivel educativo, a nivel general y por segmento de inserción ocupacional. La tabla 2 describe estos cambios en términos de variaciones interanuales. Esta información ofrece evidencias sobre lo ocurrido a lo largo del período estudiado. En primer lugar, se confirma el aumento secular, en parte por factores generacionales, en el nivel educativo promedio de la población ocupada a lo largo del período 1992-2014, expresándose esto en la caída significativa de los ocupados con hasta secundaria incompleta (37\% interanual, $-1,7$ anual) y en el aumento tanto de los trabajadores con secundario completo (51\% interanual, 2,3\% anual), como, especialmente, con estudios superiores completos ( $95 \%$ interanual, $4,3 \%$ anual). En segundo lugar, se hace evidente que este proceso no fue lineal a lo largo de los períodos estudiados ${ }^{17}$.

16 Un aumento en la inversión en capital físico e innovaciones tecnológicas, o incluso un mayor control oligopólico de los mercados, a nivel de las unidades económicas amplía la brecha de productividad entre trabajadores, de manera independiente de su nivel de escolaridad; más allá de que la demanda de calificaciones también pueda verse segmentada por este motivo. Por lo mismo, la no consideración de estas desigualdades productivas estructurales podría estar sobreestimando el papel de las primas salariales por educación.

17 En efecto, se observan diferencias según las etapas macroeconómicas por factores más probablemente vinculados con los cambios en la demanda de empleo: entre 1992-1998, en un contexto de fuertes cambios tecnológicos, con baja demanda agregada de empleo y reestructuraciones sectoriales, la demanda se concentró más en los niveles educativos medio y superior, mientras que los ocupados de baja calificación perdían empleos. 
Tabla 1. Distribución de la población ocupada por máximo nivel educativo alcanzado según sector de inserción y año seleccionado. Gran Buenos Aires: 1992, 1998, 2003 y 2014.

\begin{tabular}{|c|c|c|c|c|c|}
\hline \multirow{2}{*}{$\begin{array}{c}\text { Sector de inserción } \\
\text { Máx. nivel educativo }\end{array}$} & \multicolumn{4}{|c|}{ Año } \\
\cline { 2 - 5 } & & $\mathbf{1 9 9 2}$ & $\mathbf{1 9 9 8}$ & $\mathbf{2 0 0 3}$ & $\mathbf{2 0 1 4}$ \\
\hline \multirow{3}{*}{$\begin{array}{c}\text { Sector Privado } \\
\text { Formal }\end{array}$} & Hasta SI & $60,4 \%$ & $52,5 \%$ & $35,4 \%$ & $32,6 \%$ \\
\cline { 2 - 5 } & SC-TUI & $25,7 \%$ & $29,5 \%$ & $37,0 \%$ & $42,3 \%$ \\
\hline \multirow{3}{*}{\begin{tabular}{c} 
Sector Público* \\
\cline { 2 - 5 }
\end{tabular}} & TUC & $13,8 \%$ & $18,0 \%$ & $27,7 \%$ & $25,1 \%$ \\
\cline { 2 - 6 } & Hasta SI & $45,9 \%$ & $37,0 \%$ & $24,6 \%$ & $13,6 \%$ \\
\hline \multirow{3}{*}{$\begin{array}{c}\text { Sector Microinfor- } \\
\text { mal }\end{array}$} & SC-TUI & $25,8 \%$ & $26,2 \%$ & $32,4 \%$ & $35,2 \%$ \\
\cline { 2 - 6 } & TUC & $28,3 \%$ & $36,8 \%$ & $42,9 \%$ & $51,2 \%$ \\
\cline { 2 - 6 } & SC-TUI & $24,4 \%$ & $27,7 \%$ & $31,8 \%$ & $36,2 \%$ \\
\hline \multirow{2}{*}{$\begin{array}{c}\text { Total Población } \\
\text { Ocupada }\end{array}$} & TUC & $3,6 \%$ & $5,5 \%$ & $6,6 \%$ & $8,3 \%$ \\
\cline { 2 - 6 } & Hasta SI & $63,5 \%$ & $56,4 \%$ & $47,0 \%$ & $39,8 \%$ \\
\cline { 2 - 6 } & SC-TUI & $25,7 \%$ & $28,9 \%$ & $33,9 \%$ & $38,8 \%$ \\
\hline
\end{tabular}

*Excluye empleados públicos ocupados en programas públicos de empleo.

Fuente: Elaboración propia a partir de la EPH, INDEC (Octubre 1992 y 1998, y cuartos trimestres 2003-2014).

Tabla 2. Variación promedio anual en la distribución de la población ocupada por máximo nivel educativo alcanzado según sector de inserción y período de análisis. Gran Buenos Aires: 1992-2014.

\begin{tabular}{|c|c|c|c|c|c|}
\hline $\begin{array}{c}\text { Sector de } \\
\text { inserción }\end{array}$ & $\begin{array}{c}\text { Máx. nivel } \\
\text { educativo }\end{array}$ & $\mathbf{1 9 9 2 - 1 9 9 8}$ & $\mathbf{1 9 9 8 - 2 0 0 3}$ & $\mathbf{2 0 0 3 - 2 0 1 4}$ & $\mathbf{1 9 9 2 - 2 0 1 4}$ \\
\hline $\begin{array}{c}\text { Sector } \\
\text { Privado }\end{array}$ & Hasta SI & $-2,2$ & $-6,5$ & $-0,7$ & $-2,1$ \\
Formal & SC-TUI & 2,5 & 5,1 & 1,3 & 2,9 \\
\hline & TUC & 5,1 & 10,8 & $-0,9$ & 3,7 \\
Sector & Hasta SI & $-3,2$ & $-6,7$ & $-4,1$ & $-3,2$ \\
Público* & SC-TUI & 0,3 & 4,7 & 0,8 & 1,7 \\
\hline $\begin{array}{c}\text { Sector Mi- } \\
\text { cro Infor- } \\
\text { mal }\end{array}$ & TUC & 5,0 & 3,3 & 1,8 & 3,7 \\
\hline
\end{tabular}




\begin{tabular}{|c|c|c|c|c|c|}
\hline \multirow{2}{*}{$\begin{array}{c}\text { Total Ocu- } \\
\text { pados }\end{array}$} & Hasta SI & $-1,9$ & $-3,3$ & $-1,4$ & $-1,7$ \\
& SC-TUI & 2,1 & 3,5 & 1,3 & 2,3 \\
& TUC & 5,8 & 6,0 & 1,0 & 4,3 \\
\hline
\end{tabular}

*Excluye empleados públicos ocupados en programas públicos de empleo.

Fuente: Elaboración propia a partir de la EPH, INDEC (Octubre 1992 y 1998, y cuartos trimestres 2003-2014).

Este proceso continuó durante el período recesivo 1998-2003. Pero este sendero se interrumpió en parte en la etapa 2003-2014, en donde el mayor crecimiento de la demanda agregada de empleo, en especial hacia el mercado interno y a través de actividades de bajo requerimiento en calificaciones (construcción, industria de bienes de consumo, comercio, servicios personales, etc.), retrajo la tendencia anterior. De esta manera, en sentido confirmatorio a una serie de supuestos relativamente aceptados (Gasparini et al., 2011), si bien siguieron creciendo los puestos con trabajadores de nivel educativo medio o superior, este crecimiento tuvo lugar a una tasa mucho más baja. En parte, esto último responde a la recuperación que tuvo la demanda de empleo hacia los segmentos de bajo nivel educativo. Pero estas tendencias no se reproducen de igual manera cuando se considera el sector productivo de inserción, medido por el tipo de unidad económica. Las tablas 1 y 2 son ilustrativas en cuanto a estas diferencias:

i) Se constata las diferencias estructurales presentes en la composición educativa de la fuerza de trabajo según sector de inserción, así como su persistencia en el tiempo ${ }^{18}$.

ii) Destaca la variación positiva experimentada tanto por los ocupados con educación media como con educación superior en los tres sectores considerados, aunque con diferencias de magnitud muy notables.

iii) En tercer lugar, la información también hace evidente que estos procesos no avanzaron al mismo ritmo dependiendo del tipo de unidad económica: durante el proceso de liberalización económica, las mayores caídas en las ocupaciones de bajo nivel educativo tuvieron lugar en el sector privado formal y en el sector público, pero sólo este último continuó este mismo sendero durante el período siguiente. En cambio, para el sector microinformal, la lenta reducción de ocupaciones de baja calificación casi no registró cambios, un comportamiento que seguramente estuvo más fuertemente determinado por la oferta que por la demanda laboral.

iv) Por último, en cuanto a los cambios en la participación de los ocupados con estudios superiores, llama la atención algunos procesos coincidentes con observaciones hechas por los diferentes enfoques en debate, pero que se hacen más evidentes al segmentar por tipo de inserción. Por una parte, en efecto, la demanda de ocupaciones más calificadas crece fuertemente durante los años

18 Al respecto, destaca que, entre 1992 y 2014, el sector privado informal redujo a casi la mitad los ocupados de baja calificación (de $60 \%$ a $33 \%$ ) y el sector público modernizado siguió este mismo sendero, pero con mayor intensidad (de 46\% a 14\%), el segmento microinformal lo hizo muy por debajo de la media (de $72 \%$ a $53 \%$ ), constituyéndose en el principal sector refugio de los segmentos de baja calificación. 
noventa, a la vez que decrece post-crisis 2001-2002; en ambos casos, siendo el sector privado formal su principal protagonista. Al mismo tiempo, la demanda de empleo con educación media crece a un ritmo relativamente más parejo entre los tres sectores, antes y después del cambio del modelo macroeconómico.

Por último, la tabla 3 resume buena parte de los resultados que interesa destacar en este apartado. En principio, según estos datos, en el contexto de un aumento casi continuo de puestos ocupados por profesionales, la desigual distribución de tales capitales, lejos de reducirse, se mantuvo casi inalterada a lo largo del tiempo, resultando sus variaciones más sensibles al rimo de los ciclos económicos que a supuestas políticas de reconversión o refundación productiva ${ }^{19}$. Sólo el sector público parece haber seguido un proceso continuo de profesionalización de sus ocupados, ampliándose por lo tanto la brecha entre este sector y el resto. A su vez, la menor desigualdad relativa que aflora hacia 2014 entre los sectores privados parece estar más vinculada a una retracción en la demanda de perfiles profesionales por parte del sector privado formal, que a la leve mejora registrada en el segmento microinformal. De esta manera se confirma que acompañando el aumento en las calificaciones educativas de la fuerza de trabajo, las desigualdades entre sectores de inserción se habrían mantenido casi inalteradas en materia de distribución de recursos más calificados ${ }^{20}$.

Tabla 3. Razón de probabilidad de contar con estudios terciarios y/o universitarios completos según sector de inserción con respecto a la población ocupada. Gran Buenos Aires: $1992,1998,2003$ y 2014.

\begin{tabular}{|l|c|c|c|c|}
\hline \multirow{2}{*}{ Sector de inserción } & \multicolumn{4}{|c|}{ Años } \\
\cline { 2 - 5 } & 1992 & 1998 & 2003 & 2014 \\
\hline Sector Privado Formal & 1,312 & 1,274 & 1,621 & 1,237 \\
\hline Sector Público* & 3,230 & 3,379 & 3,188 & 3,872 \\
\hline Sector Microinformal & 0,306 & 0,338 & 0,299 & 0,334 \\
\hline Total Ocupados & 1 & 1 & 1 & 1 \\
\hline
\end{tabular}

*Excluye empleados públicos ocupados en programas públicos de empleo.

Fuente: Elaboración propia a partir de la EPH, INDEC (Octubre 1992 y 1998, y cuartos trimestres 2003-2014).

19 Estos datos son coincidentes con las evidencias presentadas por Salvia y Vera (2015), en cuanto a los efectos de los cambios en la composición educativa de los ocupados de cada sector sobre la precariedad laboral.

20 En este contexto, no cabe descartar un deterioro por el efecto "credencialismo", el cual plantea que en presencia de una demanda agregada de trabajo decreciente y una oferta de trabajadores calificados creciente, aquellos trabajadores con mayor escolaridad empiezan a tomar los puestos de los trabajadores no calificados, quienes son desplazados hacia el desempleo o el subempleo. Ese ajuste reduce el salario promedio de los trabajadores calificados por medio de un efecto de composición, pero el mercado laboral se torna más rígido para los trabajadores menos calificados, quienes pierden sus empleos o trabajan menos horas. El resultado es un aumento en la desigualdad (Maurizio, 2001). 


\section{Premios en los ingresos según nivel educativo y sector de inserción ocupacional}

Según los enfoques que centran su atención en los atributos de la fuerza de trabajo -específicamente en su nivel de educación-, cabría esperar variaciones casi automáticas en las remuneraciones y en brechas de ingresos laborales ${ }^{21}$. Sin embargo, la evidencia empírica no parece ajustar plenamente con esta teoría. Tal como se ha mencionado, una buena parte de los estudios disponibles sobre los cambios distributivos ocurridos en la Argentina durante las últimas dos décadas enfatizan la importancia que tuvo primero el aumento y luego la reducción de los premios a la educación, tanto como causa del empeoramiento de la desigualdad en los ingresos del trabajo durante el período de políticas neoliberales, como de la mejora observada en la misma durante el período de políticas heterodoxas (Cornia, 2011; Gasparini et al., 2011).

Para la década de los noventa, la evidencia permite corroborar un proceso de reasignación sectorial de la demanda de empleo, así como cambios en la composición de las cualificaciones dentro de los sectores, los cuales habrían favorecido a los trabajadores calificados, en particular a los graduados universitarios. A partir de esta mayor demanda de trabajadores calificados, la prima salarial por escolaridad habría crecido de manera significativa. De tal manera que el efecto generado por el aumento de la demanda de recursos formados, habría más que compensado la presión a la baja que generaba, por otra parte, la creciente oferta de trabajadores con estudios superiores (Gasparini et al., 2011). Pero entrando a los años 2000, diversos factores se habrían combinado para crear un sendero de distribución del ingreso más progresivo. En principio, la rápida recuperación de la crisis de 2001-2002, los ajustes salariales a la baja luego de la devaluación, la gran expansión del empleo, los cambios inducidos por los nuevos precios relativos, una actualización tecnológica más lenta, instituciones y políticas laborales más fuertes y una red de protección social más amplia, habrían operado en este sentido. En este contexto, se habría verificado una reducción de las brechas de ingreso salarial (Cornia y Martorano, 2012; Lustig et al., 2013). Esto habría ocurrido como resultado, principalmente, de una demanda de puestos de mayor calificación por debajo de la oferta de trabajadores con educación superior, y, asimismo, de un aumento en la escolaridad media en la oferta laboral, lo cual habría inducido a una reducción de la desigualdad por escolaridad entre los ocupados (Gasparini et al., 2011).

En cambio, Beccaria, Maurizio y Velázquez (2015), si bien buscan destacar el impacto igualador del proceso de regulación y afiliación a la seguridad social durante el último decenio, constatan una reducción del efecto de la educación superior sobre las primas salariales. Al respecto, se argumenta que su efecto distributivo habría estado más asociado a los cambios en la composición del empleo por nivel educativo y a la calidad de los mismos, más que a factores de mercado. Según estos autores, la reducción en las brechas salariales a partir de los años 2000, sería el resultado de un aumento de la demanda de puestos de calificación intermedios (educación media), junto con un incremento relativo mayor de estos salarios, en comparación con los

Estos planteos se encuentran tanto en producciones locales como internacionales que, al apoyarse en postulados más o menos restringidos de la teoría del capital humano, enfatizan la importancia prioritaria de esta relación para explicar las desigualdades en la distribución de los ingresos laborales (Carlson, 2002; Giménez, 2005; Herrera, 2010; Paz, 2007). 
salarios profesionales (educación superior ${ }^{22}$. Este comportamiento se explica fundamentalmente por el aumento de la demanda de empleo, la intervención de políticas laborales activas y las presiones de trabajadores y actores sindicales. Como resultado de este proceso, los salarios habrían aumentado más entre los segmentos de calificación con menos años de escolaridad, a la vez que esta evolución habría sido más regresiva para los segmentos laborales con mayor educación.

En términos generales, las predicciones planteadas por ambas perspectivas se verifican a partir de los datos presentados en las tablas 1-2 del apartado anterior. Sin embargo, corresponde en este apartado examinar si las explicaciones sobre el comportamiento de los ingresos laborales ajustan con la evidencia reunida en este trabajo, y si acaso estas evidencias no obligan a una revisión de algunos de los supuestos generalmente aceptados como válidos. ${ }^{23}$ En principio, el gráfico 1 da cuenta de la evolución de los ingresos horarios a pesos constantes de la fuerza de trabajo del Gran Buenos Aires según nivel educativo. Un primer dato que llama la atención es el particular incremento que registró la brecha de ingresos laborales entre 1992 y 1998 asociada al aumento significativo que experimentaron las remuneraciones horarias de los trabajadores con educación superior, la caída en el ingreso del segmento menos calificado y la invarianza experimentada en el caso de los trabajadores con educación media. A esta tendencia le siguió una caída entre 1998 y 2003 -como efecto de la crisis 2001-2002- en los ingresos laborales horarios en los tres segmentos; aunque mucho más marcada para los trabajadores con calificación profesional, para quienes incluso la caída habría ocurrido antes de las crisis. Llegado a este punto (2003), junto a una recuperación parcial en las remuneraciones, la brecha de ingresos laborales entre segmentos educativos tendió a aumentar -hasta 2007-, para luego comenzar a retraerse hasta llegar en 2012-2014 a los niveles más bajos de toda la serie. En general, los ingresos laborales horarios de este período estuvieron muy por debajo de los niveles alcanzados en la década anterior; destacándose en particular la imposibilidad de los segmentos profesionales de recuperar los niveles alcanzados en ese período.

22 A este respecto, Beccaria y González (2006) aclara que la "tasa de retorno promedio a un año extra de educación aumentó a lo largo de la mayor parte del período 1974-2003”. Si bien tuvo fluctuaciones y una reducción entre 1989 y 1993, "la tendencia al crecimiento reapareció desde mediados de los noventa, seguida, a partir de 2003, por una reducción que, sin embargo, no pudo compensar el crecimiento previo."

23 Pero antes de examinar la evidencia, resulta importante tener en consideración una serie de aspectos a partir de los cuales se explican eventuales diferencias entre las distintas aproximaciones: i) en este trabajo se consideraron las remuneraciones horarias a precios reales de trabajadores tanto asalariados como no asalariados; ii) se han estimado los ingresos no declarados por perceptores individuales según tipo de ocupación; y iii) se ha aplicado un empalme retrospectivo que hacen más comparables los resultados que ofrece la EPH-INDEC para el período objeto de interés. 
Gráfico 1. Evolución de la media de ingresos laborales horarios reales para los trabajadores según NIVEL EDUCATIVO. Gran Buenos Aires: 1992-2014. En pesos del $4^{\circ}$ trimestre de 2014.

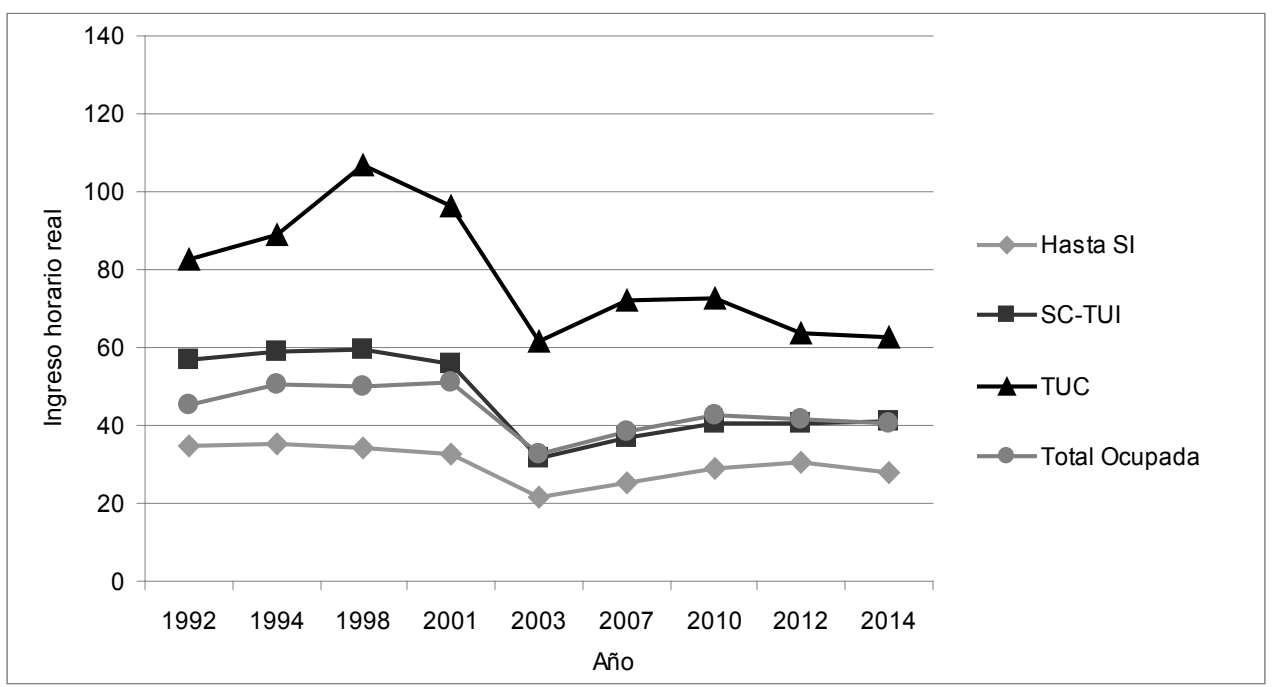

Fuente: Elaboración propia a partir de la EPH, INDEC (Octubre de 1992, 1994, 1998, 2001 y $^{\circ}$ trimestre de 2003, 2007, 2010, 2012 y 2014).

Estas evidencias parecerían refutar la tesis que afirma que habrían sido las ocupaciones de baja y media educación las que habrían contribuido a una mayor equidad distribuida durante el período de políticas heterodoxas; esto incluso considerando que el segmento de educación media siguió aumentando su participación en el total del empleo y que el segmento de baja calificación bajó el ritmo de su retracción (tablas 1-2). Por el contario, en el contexto del aumento que experimentó la participación de trabajadores con educación superior en el total del empleo, se confirmaría la tesis de que la reducción de la desigualdad en los ingresos laborales se habría debido a una retracción en las remuneraciones profesionales (Gasparini y Cruces, 2011).

Ahora bien, la evolución de la desigualdad tomando los ingresos laborales por nivel educativo ¿es la misma cuando este análisis se hace cruzado por sectores ocupacionales, en este caso: privado formal, público y microinformal? El gráfico 2 muestra la evolución registrada por los ingresos horarios de los ocupados según esta clasificación. 
Gráfico 2. Evolución de la media de ingresos laborales horarios reales para los trabajadores según SECTOR DE INSERCIÓN. Gran Buenos Aires: 1992-2014. En pesos del $4^{\circ}$ trimestre de 2014.

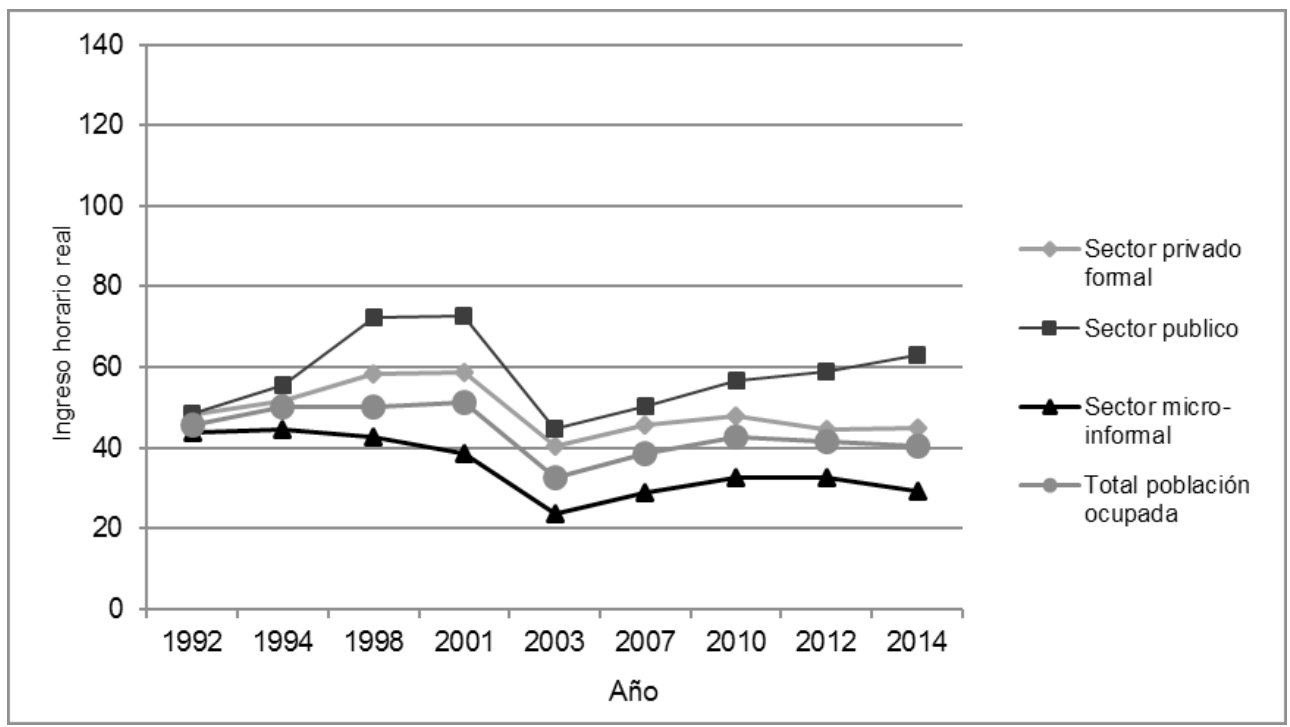

Fuente: Elaboración propia a partir de la EPH, INDEC (Octubre de 1992, 1994, 1998, 2001 y $^{\circ}$ trimestre 2003, 2007, 2010, 2012 y 2014).

En principio, los datos son coincidentes con evidencias previas (Salvia, 2012; Salvia y Vera, 2013; Salvia et al., 2015) en cuanto a dar cuenta de un giro regresivo en las brechas de ingresos laborales por sector de inserción durante la primera parte del período 1990-1998, pero no inicialmente, sino ya avanzada la década. Destaca el hecho de que los primeros años se registran las menores brechas de ingreso laboral y que las brechas mayores se observan en la fase final del modelo, previo a la crisis de 2001-2002. Durante este período, el crecimiento de la desigualdad estuvo vinculado, en primer lugar, al aumento en el nivel de los ingresos de los trabajadores del sector público y -aunque en menor medida- del sector privado formal; $\mathrm{y}$, al mismo tiempo, por la caída de los ingresos laborales del segmento de trabajadores de unidades microinformales. Es recién con la crisis 2001-2002 que los ingresos laborales vuelven a converger, aunque a niveles menores de remuneración real cualquiera sea el sector. Por último, a partir de 2003, las remuneraciones de los tres sectores comenzaron a recuperarse manteniendo casi sin variación sus diferencias de arranque. Pero esto último comenzó a modificarse luego de 2007, y ello como resultado de tres procesos: i) mayor incremento de los ingresos laborales en el sector público, ii) amesetamiento de los ingresos medios en el sector privado formal, y iii) caída en los ingresos laborales medios del segmento micro-informal.

En cualquier caso, el gráfico 2 muestra cómo a lo largo de los tres períodos considerados - al comparar las curvas correspondientes a cada sector- persisten importantes diferencias entre aquellos ocupados de unidades económicas informales y aquellos ocupados en unidades del sector formal o del sector público. Pero en contrario a lo que muchas veces se supone, habría sido el sector público y no el sector privado 
formal, el principal responsable en la ampliación de la brecha de ingresos, tanto durante la fase neoliberal como durante el período heterodoxo. Ahora bien, cabe preguntarse en qué medida este particular comportamiento no está determinado por los cambios en la composición educativa experimentada por los sectores ocupacionales. Para evaluar esta hipótesis, los gráficos 3, 4 y 5, muestran la evolución de los ingresos laborales reales por nivel educativo para cada sector de inserción.

Gráfico 3. Evolución de la media de ingresos laborales horarios reales para los trabajadores del SECTOR PRIVADO FORMAL. Gran Buenos Aires: 1992-2014. En pesos del $4^{\circ}$ trimestre de 2014.

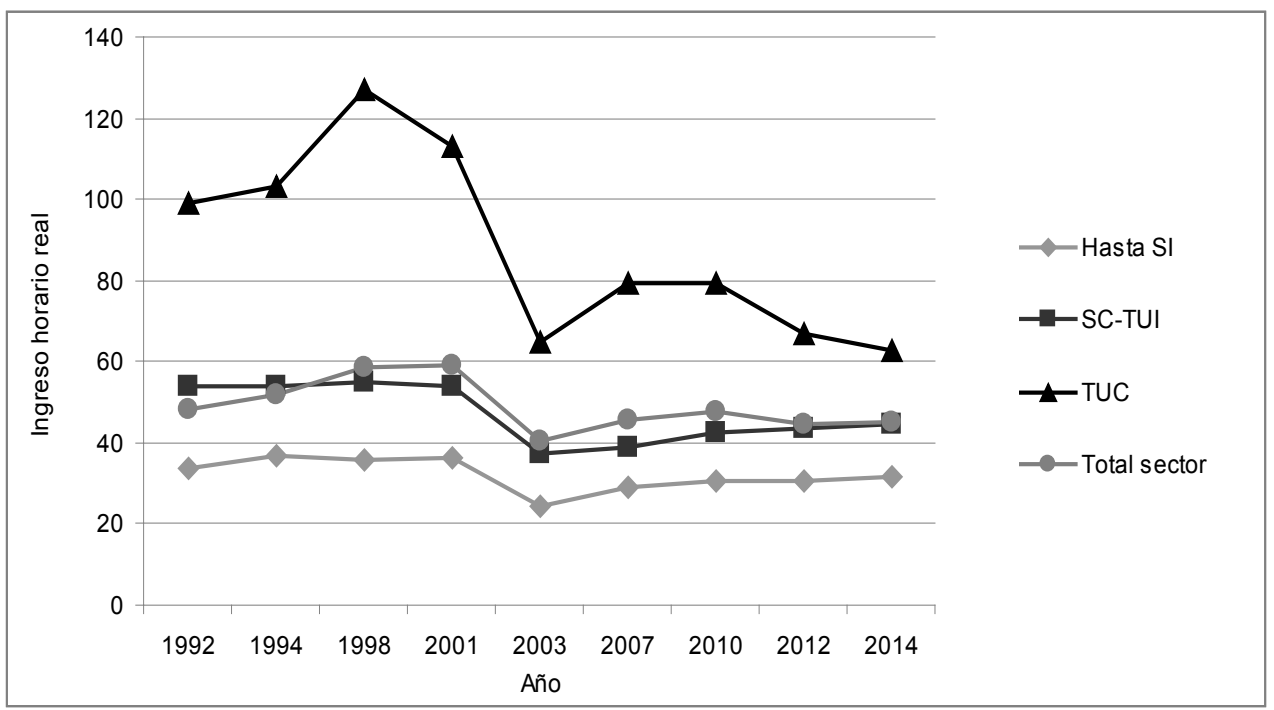

Fuente: Elaboración propia a partir de la EPH, INDEC (Octubre de 1992, 1994, 1998, 2001 y $^{\circ}$ trimestre 2003, 2007, 2010, 2012 y 2014). 
Gráfico 4. Evolución de la media de ingresos laborales horarios reales para los trabajadores del SECTOR PÚBLICO. Gran Buenos Aires: 1992-2014. En pesos del $4^{\circ}$ trimestre de 2014.

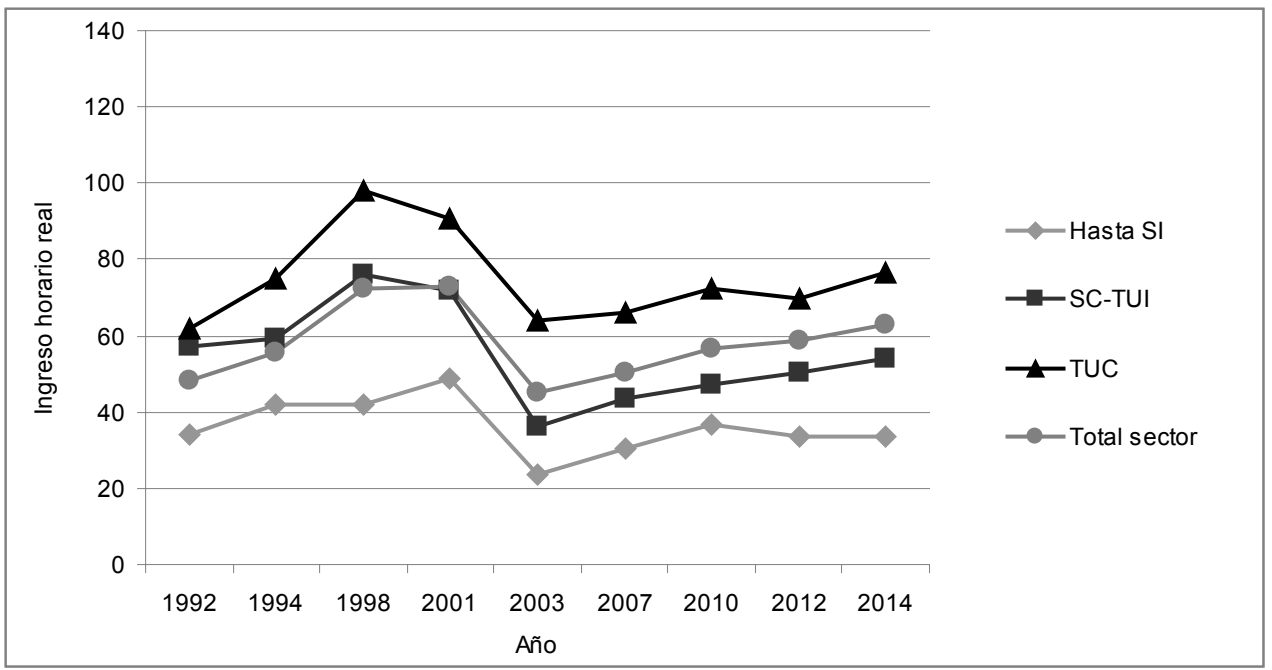

Fuente: Elaboración propia a partir de la EPH, INDEC (Octubre de 1992, 1994, 1998, 2001 y $^{\circ}$ trimestre 2003, 2007, 2010, 2012 y 2014).

Gráfico 5. Evolución de la media de ingresos laborales horarios reales para los trabajadores del SECTOR MICROINFORMAL. Gran Buenos Aires: 1992-2014. En pesos del $4^{\circ}$ trimestre de 2014.

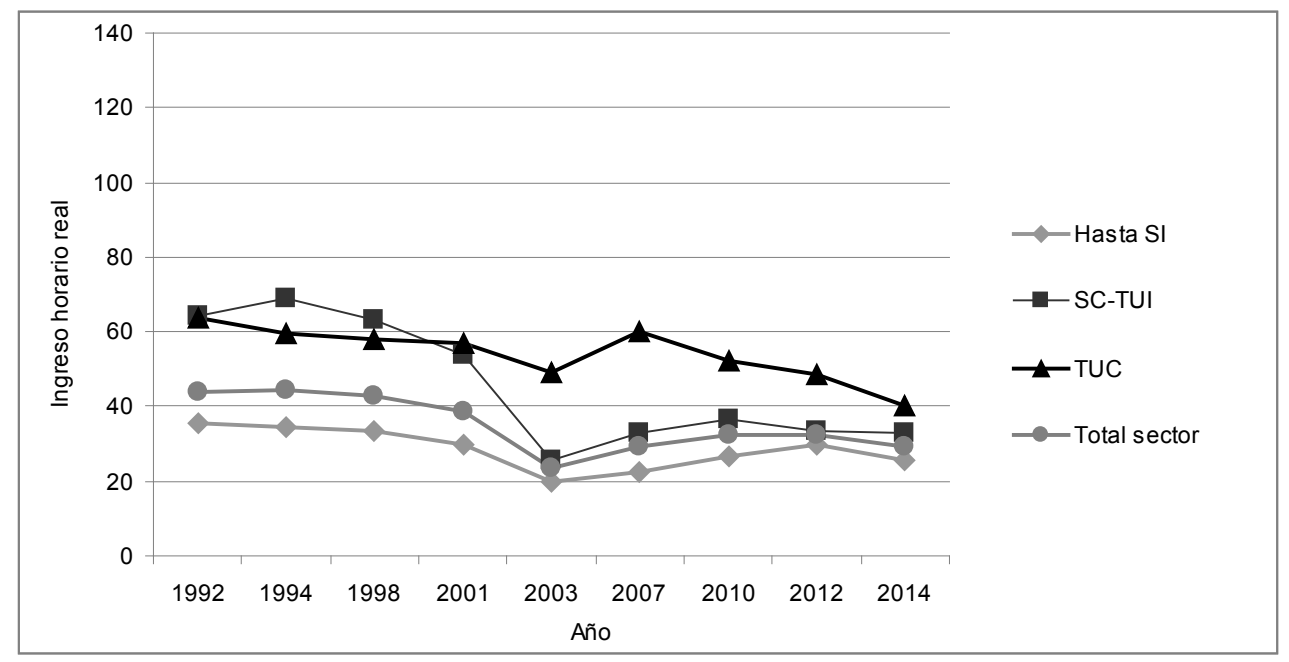

Fuente: Elaboración propia a partir de la EPH, INDEC (Octubre de 1992, 1994, 1998, 2001 y $4^{\circ}$ trimestre 2003, 2007, 2010, 2012 y 2014). 
A partir de estos datos se desprenden una serie de observaciones relevantes.

i) El movimiento que siguen los ingresos laborales por nivel educativo en el sector privado formal parece ser el principal determinante del comportamiento observado a nivel agregado; en particular, debido al mayor aumento que registraron en este sector los premios a la educación superior durante el contexto de las políticas neoliberales, y su mayor retracción con la crisis 2001-2002, a partir de lo cual la brecha vuelve a crecer, para volver a caer al final del período como efecto de la conducta de este segmento educativo.

ii) El patrón de comportamiento del ingreso de los ocupados del sector público por nivel educativo, muestra a lo largo del tiempo brechas mucho menores a las registradas por el sector privado formal; esto debido tanto a ingresos profesionales más bajos como a ingresos medios más altos en los trabajadores menos calificados. Sin embargo, su evolución muestra aumentos en la desigualdad interna acompañando a las fases en donde tuvieron lugar mejoras reales en las diferentes categorías educativas, tanto en 1992-1998 como en 2003-2014. Sólo durante la fase recesiva y más crítica del período (19982003), en el contexto de ajustes salariales en el sector público, la brecha entre estas remuneraciones tendió a achicarse.

iii) En cuanto al comportamiento de los ingresos laborales por nivel educativo en el sector microinformal, se destaca una diferencia muy marcada con respecto a los otros dos sectores. En primer lugar, la desigualdad interna entre calificaciones no habría aumentado durante la fase 1992-1998; siendo llamativo los similares niveles de ingreso que registran las categorías educativas superior y media, debido a las remunerativas significativamente más bajas - con tendencia a la caída- que presentan los ocupados con estudios superiores, como a los ingresos más altos que registran los ocupados de nivel educativo medio. Pero este comportamiento experimenta un cambio durante la etapa recesiva y de crisis (1998-2003), convergiendo con los ingresos de los trabajadores de bajo nivel educativo. En la fase de políticas heterodoxas, se observa, primero, un aumento de la desigualdad y, luego, una relativa convergencia, al igual que lo ocurrido con el sector privado formal, pero con premios a la educación superior y media por debajo de las de este sector; estas diferencias sólo se reducen en el caso de los trabajadores de baja calificación.

Las diferentes tendencias observadas en las categorías de educación por sector de inserción confirman las desigualdades estructurales que, además de otros factores, condicionan la dinámica de los premios laborales y sus desigualdades internas. Para hacer clara la evidencia empírica en que se apoya esta afirmación, la tabla 4 exhibe las brechas de ingreso de los ocupados de acuerdo a su nivel educativo y tipo de inserción laboral para los cuatro años tomados como ventana de las diferentes fases político-económicas analizadas. Estas brechas representan la distancia relativa que posee el ingreso horario medio en cada categoría respecto de la media de ingreso laboral horario para el total de los ocupados en cada año; por lo tanto, un valor mayor a 1 supone que dicha categoría se encuentra por encima de la media de ingreso del total de los trabajadores registrada para un año particular, mientras que un valor por debajo señala que dicho ingreso está por debajo del promedio general. 
Tabla 4. Evolución de las brechas entre las medias de ingresos laborales horarios reales según nivel educativo y sector de inserción, respecto del total de la fuerza de trabajo ocupada. Gran Buenos Aires: 1992, 1998, 2003 y 2014. En pesos del $4^{\circ}$ trimestre de 2014.

\begin{tabular}{|c|c|c|c|c|c|}
\hline \multirow{2}{*}{$\begin{array}{c}\text { Sector de in- } \\
\text { serción }\end{array}$} & \multirow{2}{*}{$\begin{array}{c}\text { Máx. nivel } \\
\text { educativo }\end{array}$} & \multicolumn{4}{|c|}{ Año } \\
\cline { 3 - 6 } & Hasta SI & $\mathbf{1 9 9 2}$ & $\mathbf{1 9 9 8}$ & $\mathbf{2 0 0 3}$ & $\mathbf{2 0 1 4}$ \\
\cline { 2 - 6 } & SC-TUI & 1,18 & 1,09 & 1,15 & 1,10 \\
\cline { 2 - 6 } $\begin{array}{c}\text { Sector Privado } \\
\text { Formal }\end{array}$ & TUC & 2,18 & 2,53 & 1,98 & 1,55 \\
\cline { 2 - 6 } & Total Formal & $\mathbf{1 , 0 6}$ & $\mathbf{1 , 1 6}$ & $\mathbf{1 , 2 4}$ & $\mathbf{1 , 1 1}$ \\
\hline \multirow{4}{*}{$\begin{array}{c}\text { Sector Públi- } \\
\text { co* }\end{array}$} & Hasta SI & 0,75 & 0,84 & 0,72 & 0,84 \\
\cline { 2 - 6 } & SC-TUI & 1,25 & 1,51 & 1,11 & 1,33 \\
\cline { 2 - 6 } & TUC & 1,36 & 1,95 & 1,96 & 1,90 \\
\hline \multirow{4}{*}{$\begin{array}{c}\text { Sector Mi- } \\
\text { croinformal }\end{array}$} & Total Público & $\mathbf{1 , 0 6}$ & $\mathbf{1 , 4 4}$ & $\mathbf{1 , 3 8}$ & $\mathbf{1 , 5 6}$ \\
\cline { 2 - 6 } & Hasta SI & 0,78 & 0,67 & 0,61 & 0,63 \\
\cline { 2 - 6 } & SC-TUI & 1,42 & 1,26 & 0,79 & 0,81 \\
\cline { 2 - 6 } & Total Informal & $\mathbf{0 , 9 6}$ & $\mathbf{0 , 8 5}$ & $\mathbf{0 , 7 3}$ & $\mathbf{0 , 7 2}$ \\
\hline \multirow{3}{*}{$\begin{array}{c}\text { Total Ocupa- } \\
\text { dos }\end{array}$} & Hasta SI & 0,76 & 0,68 & 0,66 & 0,69 \\
\cline { 2 - 6 } & SC-TUI & 1,25 & 1,19 & 0,98 & 1,01 \\
\cline { 2 - 6 } & TUC & 1,82 & 2,13 & 1,9 & 1,55 \\
\cline { 2 - 6 } & Total Ocupados & $\mathbf{1 , 0 0}$ & $\mathbf{1 , 0 0}$ & $\mathbf{1 , 0 0}$ & $\mathbf{1 , 0 0}$ \\
\hline
\end{tabular}

*Excluye empleados públicos ocupados en programas de empleo transitorio.

Fuente: Elaboración propia a partir de la EPH, INDEC (Octubre 1992 y 1998, y $4^{\circ}$ trimestre 2003-2014).

En conjunto, la información presentada confirma las inferencias surgidas de los gráficos 4,5 y 6 , a la vez que reafirma la importancia de la inserción se sectorial como determinante de estos comportamientos. Sin embargo, un proceso destacable que se desprende y se hace más evidente a través de los datos de la tabla 4, es el hecho de que, con excepción del sector microinformal, mientras las desigualdades laborales basadas en los premios a la educación tendieron primero a aumentar (durante las políticas de liberalización económica) y luego a caer (durante las fase de políticas heterodoxas), como efecto -aunque no únicamente- de la crisis 2001-2002, las brechas de ingresos según sector de inserción se ampliaron de manera significativa, claramente a favor de los ocupados en los sectores público y privado formal, y en marcada desventaja para el segmento de ocupados en microunidades informales. Estos datos reafirman la tesis de que una parte no menor de las desigualdades en la distribución del ingreso laboral, tienen como protagonista a las unidades económicas según sus diferenciales en materia de productividad, estructura organizacional, modo en que participan de los mercados de trabajo, regulaciones a las que están sometidas y vinculaciones con el resto del sistema económico (Salvia, 2012). 


\section{Análisis de elasticidades en los ingresos laborales horarios según nivel educativo y sector de inserción}

Para ofrecer mayor robustez a los análisis presentados se efectúa en este apartado los resultados que arrojaron una serie de modelos mincerianos ${ }^{24}$ de regresión lineal en procura de estimar el modo y la fuerza con que un conjunto de variables relevantes incidieron en los ingresos horarios laborales reales de los trabajadores, $\mathrm{y}$, en ese marco, evaluar su capacidad para dar cuenta de desigualdades endógenas y cambios en el tiempo ${ }^{25}$. Debido a la distinta prevalencia que presentan las relaciones salariales en unidades económicas ubicadas en uno u otros sectores de la estructura productiva, y dada la importancia que tiene la categoría salarial en la percepción de ingreso por parte de la fuerza de trabajo, estas ecuaciones también se ajustan segmentando a la población de ocupados en asalariados y no asalariados. El examen de las elasticidades en los ingresos laborales para asalariados y no asalariados ofrece un escenario analítico más preciso y robusto para la evaluación de nuestras hipótesis ${ }^{26}$.

En este sentido, la tesis que subyace a la aplicación de estos modelos es que los factores estructurales ejercen una influencia dominante y creciente en el tiempo sobre las diferencias en los ingresos laborales horarios de la fuerza de trabajo; incluso, controlando los efectos que tienen sobre dichos ingresos la educación formal, así como también otros factores fuertemente asociados a la demanda agregada de empleo (ramas de actividades y categoría ocupacional). En el caso de las ramas de actividad, la posibilidad de controlar su efecto específico resulta muy importante debido a su particular correlación con los sectores de inserción ocupacional, así como también, aunque en menor medida, con los niveles educativos de la fuerza de trabajo. De esta manera, las variables consideradas en estos modelos fueron: a) el nivel educativo alcanzado (menos de secundario incompleto, secundario completo/ terciario o universitario incompleto, y universitario/terciario completo); b) la rama de actividad (industria, construcción, comercio, servicios, transporte y servicio doméstico); y c) el sector económico-ocupacional de inserción (público, privado formal y micro informal). ${ }^{27}$ En términos formales, el modelo ajustado para cada ventana temporal queda representado a través de la siguiente ecuación (1).

24 Mincer (1975) elaboró una función de ingreso para explicar el salario real de un trabajador en función de sus años de escolaridad y de otras características. La estimación de la función del ingreso permite calcular la tasa de retorno de la educación o de otros factores intervinientes en la ecuación.

25 El modelo de regresión múltiple basado en el método de mínimos cuadrados consiste en la elaboración de una ecuación que permita aproximarse al valor asumido por una variable numérica en función de la presencia o ausencia de valores correspondientes a otras, así como el peso que cada una de éstas tenga en la predicción de la variable explicada. Para tal efecto se aplica un modelo de regresión lineal múltiple sobre el logaritmo natural de los ingresos laborales horarios. En este caso se analiza el impacto de una serie de características referidas a la unidad económica, el puesto de trabajo y el capital educativo de los trabajadores sobre la elasticidad de los ingresos percibir. La transformación logarítmica del ingreso permite una lectura de la elasticidad de los ingresos frente a un cambio en una unidad en las variables predictoras.

26 Si bien se parte en este trabajo de un enfoque diferente, la mayor parte de los pocos estudios para el caso argentino restringen sus análisis a los ingresos salariales.

27 Dado el carácter no métrico de las variables independientes consideradas en el modelo teórico se adoptó el criterio de transformar las categorías de cada variable nominal en variables "dummy" ( 0 para ausencia y 1 para presencia de la característica), excluyendo en cada caso una categoría de comparación (cuya incidencia estimada es representada de manera indiferenciada por la constante). 


\section{$\operatorname{Ln} \mathbf{Y}=\beta_{0}+H . \mathbf{H}+Z . \mathbf{Z}+L \cdot \mathbf{L}+\mu(1)$}

En este sentido, Ln y representa el logaritmo natural de los ingresos horarios de los trabajadores para cada año de análisis. El factor $\mathrm{H}$ constituye el efecto de los niveles educativos de la fuerza de trabajo; el componente $\mathrm{Z}$ expresa la influencia de las ramas de actividad; y el factor L considera el efecto de las variables correspondientes al sector económico-ocupacional. El término Bo expresa el valor de la constante, la cual expone el efecto indiferenciado de las categorías de comparación de las variables predictores. Por último, el factor $\mu$ representa los efectos sobre la variable endógena ignorados por el modelo.

Al segmentar por tipo de relación laboral (asalariada y no asalariada), el modelo ajustado para cada ventana temporal se representa a través de dos ecuaciones separadas, cada una dando cuenta de un análisis de elasticidad que se integra de los mismos componentes -nivel educativo, rama de actividad y sector de empleo- pero separando los universos de acuerdo al tipo de ingresos.

$$
\begin{aligned}
& L n \mathbf{W}=\beta_{0}+H \cdot \mathbf{H}+Z . \mathbf{Z}+L \cdot \mathbf{L}+\mu(2) \\
& L n \pi=\beta_{0}+H \cdot \mathbf{H}+Z \cdot \mathbf{Z}+L \cdot \mathbf{L}+\mu(3)
\end{aligned}
$$

En la ecuación (2) se representa el logaritmo natural de los ingresos horarios de los trabajadores asalariados para cada año de análisis. En este caso, las variaciones de ingreso medidas corresponden a $\mathrm{W}$, asociada al ingreso procedente del trabajo asalariado. En la ecuación (3) se representa el logaritmo natural de los ingresos horarios de trabajadores autónomos y patrones o empleadores. Aquí, las variaciones se significan con el símbolo $\pi$, comúnmente asociado a retribuciones del capital y utilizado en este trabajo para identificar los ingresos laborales de carácter autónomo, utilidades y beneficios.

La tabla 5 presenta los Coeficientes B de regresión y los coeficientes de correlación parcial estimados por el método de mínimos cuadrados sobre el logaritmo natural de los ingresos horarios reales de los trabajadores ocupados en el área metropolitana del Gran Buenos Aires, sin distinguir su categoría laboral. Según los resultados alcanzados, los $\mathrm{R}^{2}$ dan cuenta -en todos los años considerados- de una bondad de ajuste del modelo de alrededor de $20 \%$.

i) En primer lugar, el modelo general (1) confirma la tendencia en cuanto al aumento de los retornos educativos con educación superior durante la etapa de políticas de liberalización económica (1992-1998). Sin embargo, tal como fue también señalado, la brecha entre los ingresos horarios de los ocupados con educación media y los ingresos de los ocupados de bajo nivel educativo, no cambia de manera sensible. Para el mismo período, destaca el hecho de una elasticidad del ingreso laboral negativa en 1992 para los ocupados en el sector público o privado formal con respecto a los ocupados en microunidades informales (controlando los efectos nivel educativo y rama de actividad). Pero este particular fenómeno tiende a disiparse al final de esta etapa; esto debido fundamentalmente tanto a la caída de los ingresos de las ocupaciones microinformales como al aumento de los ingresos labores de las otras dos categorías. 
ii) En segundo lugar, para el período 1998-2003, la fuerte caída experimentada por los retornos educativos, tanto superiores o intermedios, torna más evidente que la crisis 2001-2002 fue el principal factor igualador en la distribución del ingreso laboral por nivel educativo. En cambio, para el mismo período, los ingresos laborales de los ocupados en las microunidades informales pierden posiciones frente a la menor pérdida de ingresos en los trabajadores de los sectores público y privado formal. Al mismo tiempo, destaca una profundización entre las diferencias registradas en niveles de ingresos laboral según rama de actividad: la industria y los servicios, y en menor medida la construcción, sobresalen como las ramas de mayor elasticidad positiva, en comparación con el comercio y otras aún más rezagadas.

iii) Por último, durante la fase de políticas heterodoxas (2003-2014), si bien tiene lugar una caída en los premios por educación superior y media, esta no resulta en ninguno de los dos casos significativa en términos interanuales. Sin embargo, tuvo lugar al mismo tiempo un aumento relevante en las elasticidades por remuneración laboral en los ocupados de los sectores privado-formal y público; justamente, en donde hay mayor concentración de perfiles de educación media y superior. Esto en detrimento de los ocupados en el sector miroinformal, cualquiera sea su nivel de educación. En este marco, el comportamiento de las elasticidades de ingreso según ramas de actividad resulta relevante. Si bien se achica la brecha, incluso para el caso de la industria, despunta la rama financiera por sobre el resto; a la vez que las remuneraciones de los ocupados en comercio y otras actividades continúan en proceso descendente.

Tabla 5. Evolución de la incidencia de las variables seleccionadas sobre el logaritmo natural de los ingresos horarios de los OCUPADOS. Gran Buenos Aires: 1992-19982003-2014.

\begin{tabular}{|c|c|c|c|c|}
\hline \multirow{2}{*}{ Variables introducidas } & \multicolumn{4}{|c|}{ Año } \\
\hline & 1992 & 1998 & 2003 & 2014 \\
\hline TUC & $\begin{array}{c}, 776 * * * \\
(, 370)\end{array}$ & $\begin{array}{c}1,009 * * * \\
(, 460)\end{array}$ & $\begin{array}{c}, 693 * * * \\
(, 287)\end{array}$ & $\begin{array}{c}, 568 * * * \\
(, 289)\end{array}$ \\
\hline SC-TUI & $\begin{array}{c}, 364 * * * \\
(, 245)\end{array}$ & $\begin{array}{c}419 * * * \\
(, 245)\end{array}$ & $\begin{array}{c}, 285 * * * \\
(, 142)\end{array}$ & $\begin{array}{c}, 263 * * * \\
(, 159)\end{array}$ \\
\hline Hasta SI & - & - & - & - \\
\hline Sector Público¥ & $\begin{array}{c}-, 230 * * * \\
(-, 108)\end{array}$ & $\begin{array}{l}, 042 \\
(, 017)\end{array}$ & $\begin{array}{c}344 * * * \\
(, 117)\end{array}$ & $\begin{array}{c}, 477 * * * \\
(, 195)\end{array}$ \\
\hline Sector Privado Formal & $\begin{array}{l}-, 039 * \\
(-, 029)\end{array}$ & $\begin{array}{c}, 066^{* *} \\
(, 038)\end{array}$ & $\begin{array}{c}, 376 * * * \\
(, 194)\end{array}$ & $\begin{array}{c}, 383 * * * \\
(, 236)\end{array}$ \\
\hline Sector Microinformal & - & - & - & - \\
\hline Industria & $\begin{array}{l}, 010 \\
(, 007)\end{array}$ & $\begin{array}{c}153 * * * \\
(, 074)\end{array}$ & $\begin{array}{c}165 * * * \\
(, 063)\end{array}$ & $\begin{array}{l}, 002 \\
(, 001)\end{array}$ \\
\hline
\end{tabular}




\begin{tabular}{|c|c|c|c|c|}
\hline Construcción & $\begin{array}{l}, 033 \\
(, 011)\end{array}$ & $\begin{array}{c}, 209 * * * \\
(, 070)\end{array}$ & $\begin{array}{l}, 130 * \\
(, 034)\end{array}$ & $\begin{array}{l}, 051 \\
(, 017)\end{array}$ \\
\hline Servicios & $\begin{array}{l}, 104 * * \\
(, 076)\end{array}$ & $\begin{array}{c}, 225^{* * *} * \\
(, 142)\end{array}$ & $\begin{array}{c}314 * * * \\
(, 165)\end{array}$ & $\begin{array}{c}146 * * * \\
(, 090)\end{array}$ \\
\hline Transporte & $\begin{array}{l}, 018 \\
(, 007)\end{array}$ & $\begin{array}{c}-, 116 * * \\
(-, 041)\end{array}$ & $\begin{array}{c}-, 100 \\
(-, 029)\end{array}$ & $\begin{array}{l}-, 076 * \\
(-, 026)\end{array}$ \\
\hline Otras ramas & $\begin{array}{c}, 002 * * \\
(, 000)\end{array}$ & $\begin{array}{c}-, 017 \\
(-, 001)\end{array}$ & $\begin{array}{c}-, 125 \\
(-, 018)\end{array}$ & $\begin{array}{c}-, 172 * * \\
(-, 034)\end{array}$ \\
\hline Comercio & - & - & - & - \\
\hline Constante & 3,288 & 3,101 & 2,654 & 2,934 \\
\hline R2 corregido & , 161 & ,265 & , 187 & ,211 \\
\hline
\end{tabular}

Excluye empleados públicos ocupados en programas de empleo transitorio.

Fuente: Elaboración propia a partir de la EPH, INDEC (octubre 1992 y 1998, y $4^{\circ}$ trimestre 2003-2014).

*Nivel de significancia de $\mathrm{p}<0,1$

$* *$ Nivel de significancia de $\mathrm{p}<0,05$

$* * *$ Nivel de significancia de $\mathrm{p}<0,01$

En términos generales, mientras gana relevancia la educación formal en la determinación de la distribución del ingreso durante la fase de reformas neoliberales, con el advenimiento de la crisis 2001-2002 y la posterior fase de políticas heterodoxas, se confirma un descenso sensible en la prima por nivel educativo. Ahora bien, al mismo tiempo que esto ocurría, la heterogeneidad sectorial siguió ganando poder explicativo en la desigual distribución de los ingresos laborales, esto debido tanto a la caída general que experimentaron los premios de ingresos ofrecidos por el sector microinformal, como a la creciente concentración de trabajadores de baja calificación en este segmento.

Las tablas 6 y 7 replican los resultados del mismo modelo de regresión, pero separando el universo de los trabajadores ocupados en asalariados y no asalariados. Dicha separación da lugar a algunas modificaciones en el desempeño de los coeficientes B, la intensidad y la elasticidad de la relación entre los ingresos y las diferentes variables introducidas en los modelos. 
Tablas 6. Evolución de la incidencia de las variables seleccionadas sobre el logaritmo natural de los ingresos horarios de trabajadores ASALARIADOS. Gran Buenos Aires: 1992-1998-2003-2014.

\begin{tabular}{|c|c|c|c|c|}
\hline \multirow{2}{*}{ Variables introducidas } & \multicolumn{4}{|c|}{ Año } \\
\hline & 1992 & 1998 & 2003 & 2014 \\
\hline \multirow{2}{*}{ TUC } &, $743 * * *$ &, $933 * * *$ &, $745 * * *$ &, $627 * * *$ \\
\hline & $(, 40)$ & $(, 48)$ & $(, 38)$ & $(, 37)$ \\
\hline \multirow{2}{*}{ SC-TUI } &, $412 * * *$ &, $432 * * *$ &, $313 * * *$ &, $265 * * *$ \\
\hline & $(, 31)$ & $(, 29)$ & $(, 19)$ & $(, 18)$ \\
\hline Hasta SI & - & - & - & - \\
\hline \multirow{2}{*}{ Sector público¥ } &, $127 * * *$ &, $270 * * *$ &, $303 * * *$ &, $480 * * *$ \\
\hline & $(, 10)$ & $(, 14)$ & $(, 14)$ & $(, 25)$ \\
\hline \multirow{2}{*}{ Sector privado formal } & 015 &, $196 * * *$ &, $316 * * *$ &, $344 * * *$ \\
\hline & $(, 01)$ & $(, 14)$ & $(, 19)$ & $(, 23)$ \\
\hline Sector microinformal & - & - & - & - \\
\hline \multirow{2}{*}{ Industria } & 046 &, $211 * * *$ &, $176 * * *$ & 015 \\
\hline & $(, 03)$ & $(, 12)$ & $(, 08)$ & $(, 01)$ \\
\hline Construcción & $\begin{array}{l}, 078 \\
(, 03)\end{array}$ & $\begin{array}{c}, 270 * * * \\
(, 09)\end{array}$ & $\begin{array}{l}, 090 \\
(, 02)\end{array}$ & $\begin{array}{l}-, 034 \\
(-, 01)\end{array}$ \\
\hline \multirow{2}{*}{ Servicios } &, $092 * * *$ &, $239 * * *$ &, $302 * * *$ &, $059 *$ \\
\hline & $(, 08)$ & $(, 17)$ & $(, 18)$ & $(, 04)$ \\
\hline \multirow{2}{*}{ Transporte } &,- 024 &,$- 083 * *$ &,$- 098 *$ &, $000 * *$ \\
\hline & $(-, 01)$ & $(-, 04)$ & $(-, 04)$ & $(, 00)$ \\
\hline Otras ramas & $\begin{array}{l}, 109 \\
(, 02)\end{array}$ & $\begin{array}{c}.233 * * \\
(, 04)\end{array}$ & $\begin{array}{l}, 100 \\
(, 02)\end{array}$ & $\begin{array}{c}-, 116^{*} \\
(-, 03)\end{array}$ \\
\hline Comercio & - & - & - & - \\
\hline Constante & 3,047 & 2,881 & 2,513 & 2,961 \\
\hline R2 corregido & ,216 & ,319 & ,238 & ,214 \\
\hline
\end{tabular}

Excluye empleados públicos ocupados en programas de empleo transitorio.

Fuente: Elaboración propia a partir de la EPH, INDEC (Octubre 1992 y 1998, y $4^{\circ}$ trimestre 2003-2014).

*Nivel de significancia de $\mathrm{p}<0,1$

$* *$ Nivel de significancia de $\mathrm{p}<0,05$

$* * *$ Nivel de significancia de $\mathrm{p}<0,01$ 
En referencia a los ingresos salariales (tabla 6), una primera observación es que, para todos los años considerados, los R2 de los modelos generados dan cuenta de una mayor bondad de ajuste que a nivel general. Sin embargo, el impacto educativo sobre los cambios en los premios salariales, a lo largo de tiempo, no varía significativamente de lo constatado a nivel agregado; incluso el hecho de que la mayor caída en estas brechas tuvo lugar con la crisis 2001-2002, con efectos mucho menos relevantes durante la etapa heterodoxa de políticas laborales más activas en materia de protección laboral. Pero una clara diferencia entre el modelo general y el modelo ajustado para los asalariados se concentra en el impacto de los sectores público y privado-formal, los cuales muestran en este caso (al controlarse por el efecto que generan las ramas de actividad y el nivel educativo), un aumento casi ininterrumpido de su impacto positivo sobre las remuneraciones de sus ocupados, en comparación con los asalariados de las unidades microinformales.

En cuanto a los ingresos no asalariados (Tabla 7), los resultados alcanzados resultan similares en cuanto a bondad de ajuste para los dos primeros años (1992-1998), a la vez que los R2 pierden capacidad explicativa en los dos últimos años del período (2003-2014). En este contexto, los premios por educación siguen una evolución similar a la de los trabajadores asalariados, pero con brechas de ingresos menos favorables para los ocupados con estudios superiores, y algo más favorables para los segmentos con educación media, sobre todo durante la última fase político-económica. En relación al premio al sector privado formal (patrones o profesionales independientes), con respecto a la de los patrones y cuenta propias (con tareas no profesionales) de micro unidades informales, se hace evidente que las brechas en favor del primero no experimentaron cambios significativos a lo largo del tiempo; eventualmente, se habrían elevado un poco durante las crisis 2001-2002.

Tabla 7. Evolución de la incidencia de las variables seleccionadas sobre el logaritmo natural de los ingresos horarios de trabajadores NO ASALARIADOS. Gran Buenos Aires: 1992-1998-2003-2014.

\begin{tabular}{|c|c|c|c|c|}
\hline \multirow{2}{*}{ Variables introducidas } & \multicolumn{4}{|c|}{ Año } \\
\cline { 2 - 5 } & $\mathbf{1 9 9 2}$ & $\mathbf{1 9 9 8}$ & $\mathbf{2 0 0 3}$ & $\mathbf{2 0 1 4}$ \\
\hline \multirow{2}{*}{ TUC } &, $338^{* * *}$ &, $629^{* * *}$ &, $407^{* * *}$ &, $257^{* * *}$ \\
\cline { 2 - 5 } & $(, 13)$ & $(, 23)$ & $(, 12)$ & $(, 09)$ \\
\hline \multirow{2}{*}{ SC-TUI } &, $186^{* * *}$ &, $361^{* * *}$ &, $223^{* * *}$ &, $279^{* * *}$ \\
\cline { 2 - 5 } & $(, 11)$ & $(, 16)$ & $(, 09)$ & $(, 14)$ \\
\hline Hasta SI & - & - & - & - \\
\hline \multirow{2}{*}{ Sector privado formal } &, $642^{* * *}$ &, $660^{* * *}$ &, $751^{* * *}$ &, $625^{* * *}$ \\
\cline { 2 - 5 } & $(, 269)$ & $(, 14)$ & $(, 21)$ & $(, 22)$ \\
\hline Sector microinformal & - & - & - & - \\
\hline \multirow{2}{*}{ Industria } &, 061 &, $219^{* * *}$ &, 145 &,- 110 \\
\cline { 2 - 5 } & $(, 03)$ & $(, 07)$ & $(, 04)$ & $(-, 04)$ \\
\hline
\end{tabular}




\begin{tabular}{|c|c|c|c|c|}
\hline \multirow{2}{*}{ Construcción } & $\begin{array}{c}-, 005 \\
(, 00)\end{array}$ & $\begin{array}{c}, 188 * * * \\
(, 06)\end{array}$ & $\begin{array}{c}, 149 \\
(, 04)\end{array}$ & $\begin{array}{c}, 122 \\
(, 06)\end{array}$ \\
\hline \multirow{2}{*}{ Servicios } &, $263 * * *$ &, $324 * * *$ &, $295 * * *$ &, $320 * * *$ \\
\cline { 2 - 5 } & $(, 15)$ & $(, 15)$ & $(, 11)$ & $(, 15)$ \\
\hline \multirow{2}{*}{ Transporte } &, 100 &,- 123 &, 033 &,$- 338^{* *}$ \\
\cline { 2 - 5 } & $(, 03)$ & $(-, 03)$ & $(, 01)$ & $(-, 07)$ \\
\hline \multirow{2}{*}{ Otras ramas } &,$- 474 * *$ & $-1,051 * * *$ &,$- 472 * *$ &,$- 460 *$ \\
$(-, 05)$ & $(-, 08)$ & $(-, 06)$ & $(-, 05)$ \\
\hline Comercio & - & - & - & - \\
\hline Constante & 3,422 & 3,227 & 2,666 & 2,912 \\
\hline R2 corregido &, 206 &, 286 &, 120 &, 144 \\
\hline
\end{tabular}

Fuente: Elaboración propia a partir de la EPH, INDEC (Octubre 1992 y 1998, y $4^{\circ}$ trimestre 2003-2014).

$*$ Nivel de significancia de $\mathrm{p}<0,1$

$* *$ Nivel de significancia de $\mathrm{p}<0,05$

$* * *$ Nivel de significancia de $\mathrm{p}<0,01$

\section{Comentarios finales}

La mayor parte de los estudios sobre la distribución del ingreso durante las últimas décadas en la Argentina enfatizan la importancia que tuvieron los premios a la educación como causa, tanto del empeoramiento como de las mejoras observadas en la distribución del ingreso. Desde otra perspectiva, algunos estudios enfatizan los cambios en las políticas y las regulaciones laborales, y sus efectos sobre las tasas de participación de los trabajadores afiliados a la Seguridad Social. Sin desconocer estos aportes, este trabajo examinó nuevas evidencias empíricas sobre las principales tendencias que exhibe la relación entre el nivel educativo, la inserción sectorial y los ingresos laborales de la fuerza de trabajo ocupada, asumiendo como perspectiva de análisis la tesis de la heterogeneidad estructural. En tal sentido, el estudio pondera los factores estructurales del sistema económico y sus efectos sobre los factores productivos, la segmentación de los mercados de trabajo y el acceso a desiguales remuneraciones laborales.

Retomando esta perspectiva, los cambios observados en la distribución del ingreso laboral durante diferentes fases político económicas del período 1992-2014. Se interrogó sobre: i) el sentido de los cambios ocurridos en los perfiles educativos de la mano de obra según sector; ii) el comportamiento de los ingresos laborales horarios según el nivel educativo y tipo de unidad económica de inserción laboral; y iii) los efectos de una persistente coexistencia de estratos de productividad divergentes al interior de la estructura productiva y del mercado de trabajo sobre la relación entre educación y remuneraciones.

Dadas las limitaciones que ofrece la información disponible, el análisis empírico se restringió al área metropolitana del Gran Buenos Aires, comparando tres perío- 
dos macroeconómicos diferentes. En primer lugar, una de políticas de liberalización económica de inspiración neoliberal (1992-1998); en segundo lugar, una etapa en donde este modelo ingresa a una fase de crisis terminal (1998-2003); y, por último, un período de largo crecimiento del empleo, acompañado de políticas "heterodoxas" orientadas al mercado interno y políticas activas en materia de protección laboral y social (2003-2014).

A partir de este esquema, se examinaron las diferentes líneas interpretativas y evidencias que respaldan los actuales esfuerzos por explicar los cambios ocurridos en la distribución del ingreso laboral, ponderando el debate acerca del papel que han tenido durante los últimos años los premios por educación, las políticas laborales y las desigualdades sectoriales. Se brindaron evidencias que constatan los cambios ocurridos en los perfiles educativos de la población ocupada del Gran Buenos Aires para el período estudiado, introduciendo como dimensión de control el sector de inserción económico-ocupacional. En este sentido, se dejó constancia de que las mejoras educativas a nivel general no se reproducen de la misma manera al interior de los diferentes sectores ocupacionales. En particular, fue posible destacar tanto la creciente concentración de trabajadores con estudios superiores en el sector público, como de trabajadores de bajo nivel educativo en el sector microinformal.

En este marco, el cuarto apartado evaluó la senda recorrida por los ingresos laborales reales según nivel educativo y sector de inserción de los ocupados, analizando este comportamiento en términos de brechas de desigualdad a lo largo de las diferentes etapas político-económicas del período. Ese análisis permitió examinar las tesis en debate dando cuenta de una serie de hallazgos importantes: i) si bien los premios educativos tendieron a converger, tal como describen los estudios en la materia, la mayor parte de la reducción en las brechas por educación ocurridas durante los años 2000 tuvieron lugar durante y/o inmediatamente después de las crisis 2001-2002, debiéndose relativizar los efectos imputados al cambio en los mercados y/o en las políticas laborales durante el período heterodoxo; ii) en sentido inverso, los premios por inserción sectorial incrementaron la desigualdad en la distribución de los ingresos laborales, segmentando incluso el efecto educativo sobre los ingresos al interior de cada sector; y iii) un resultado evidente que dejan las tenencias analizadas fue el mayor "empobrecimiento" relativo de los ingresos a los que acceden los trabajadores ocupados en unidades microinformales, así como la persistencia de brechas estructurales que afectan especialmente a estos segmentos.

Por último, una serie de modelos de regresión lineal permitieron confirmar de manera más robusta que, sin descartar el eventual efecto sobre los ingresos que pudieron haber ejercido a lo largo del tiempo los cambios en la demanda de empleo, la oferta educacional y las políticas laborales, los sectores económico-ocupacionales constituyen una fuente central en los procesos de desigualdad/igualación distributiva a nivel laboral. Estas tendencias fueron corroboradas tanto para el total de ocupados como para los particulares universos de trabajadores asalariados y no asalariados.

Cabe entonces concluir que aquellos argumentos que predican sobre los cambios ocurridos en la distribución de los ingresos laborales en la Argentina a partir de los atributos educativos de la oferta y la demanda de calificaciones, así como también aquellos que proponen explicaciones institucionalistas, resultan insuficientes para entender cabalmente los cambios distributivos ocurridos al interior de la estructura económico-ocupacional. En este sentido, el análisis sectorial del mercado de trabajo, inspirado en el enfoque estructuralista, resulta no sólo plausible, pertinente y eficaz 
para complementar estos análisis, sino que constituye una clave fundamental para comprender el modo en que persisten y se reproducen las desigualdades económicas en sistemas sociales afectados por marcadas heterogeneidades estructurales.

\section{Referencias bibliográficas}

Beccaria, L., y González, M. (2006). "Impactos de la dinámica del mercado de trabajo sobre la distribución del ingreso y la pobreza en Argentina”. Problemas Del Desarollo, Revista Latinoamericana de Economía, 37(146), 97-120.

Beccaria, L., y Maurizio, R. (2012). "Reversión y continuidades bajo dos regímenes macroeconómicos diferentes. Mercado de trabajo e ingresos en Argentina, 1990-2010". Desarrollo Económico, 52(206), 205-228.

Beccaria, L., Maurizio, R., y Vázquez, G. (2015). “Desigualdad e informalidad en América Latina: el caso de la Argentina". En V. Amarante y R. Arim (Eds.), Desigualdad e informalidad. Un análisis de cinco experiencias latinoamericanas (pp. 89-128). Santiago de Chile: CEPAL.

Becker, G. S. (1962). Investment in Human Capital: A Theoretical Analysis. The Journal of Political Economy.

Bourguignon, F., Ferreira, F. H. G., y Lustig, N. (2004). The microeconomics of income distribution. Dynamics in East Asia and Latin America. New York: World Bank.

Carlson, B. (2002). "Educación y mercado del trabajo en América Latina frente a la globalización". Revista de La CEPAL 77, 1-141.

CELS. (2009). Presentación de recurso de reconsideración con recurso jerárquico en subsidio. Solicitan medidas.

CEPAL. (2012). Eslabones de la desigualdad Heterogeneidad estructural, empleo y protección social. Nueva York: Naciones Unidas.

Chena, P. I. (2010). "La heterogeneidad estructural vista desde tres teorías alternativas: el caso de Argentina". Comercio Exterior, 60(2), 99-115.

Cimoli, M., Primi, A., y Pugno, M. (2006). "Un modelo de bajo crecimiento: la informalidad como restricción estructural”. Revista CEPAL, 88, 89-107.

Cornia, G. A. (2011). "Economic Integration, Inequality and growth: Latin America vs. the European economies in transition". DESA Working Paper No. 101, 2(2), 1-31.

Cornia, G. A., y Martorano, B. (2012). Development policies and income inequality in selected developing regions, 1980-2010 (Discussion Papers No. 210). Geneva.

Cruces, G., y Gasparini, L. (2009). Los determinantes de los cambios en la desigualdad de ingresos en Argentina (Documentos de Trabajo sobre Políticas Sociales No. 5). Buenos Aires.

Damill, M., Frenkel, R., y Rapetti, M. (2015). "Macroeconomic Policy in Argentina During 2002-2013”. En Comparative Economic Studies (pp. 1-32).

Davis, K., y Moore, W. E. (1945). "Some principles of stratification”. American Sociological Review, 10(4), 242-249.

Di Filippo, A., y Jadue, S. (1976). "La Heterogeneidad Estructural: concepto y dimensiones". El Trimestre Económico, 43(169), 167-214.

Donza, E. (2015). "Cambios en las capacidades de consumo en la estructura social urbana. Argentina, 1992-2012”. En J. Lindenboim y A. Salvia (Eds.), Hora de balance. Proceso de acumulación, mercado de trabajo y bienestar. Argentina, 2002-2014. Buenos Aires: EUDEBA. 
Esquivel, V. (2007). “Género y diferenciales de salarios en la Argentina”. En S. Novick y H. Palomino (Eds.), Estructura productiva y empleo. Un enfoque transversal. Buenos Aires: Ministerio de Trabajo, Empleo y Seguridad Social de la Nación.

Galiani, S., y Sanguinetti, P. (2003). «The impact of trade liberalization on wage inequality: evidence from Argentina". Journal of Development Economics, 72(2), 497-513.

Gasparini, L., Galiani, S., Cruces, G., y Acosta, P. (2011). Educational Upgrading and Returns to Skills in Latin America: Evidence from a Supply-Demand Framework, 19902010 (Human Development-Social Protection No. 5921).

Gasparini, L., y Lustig, N. (2011). The rise and fall of income inequality in Latin America (No. 1110). Tulane Economics Working Paper Series. New Orleans.

Germani, G. (1963). "La movilidad social en la Argentina". En S. M. Lipset y R. Bendix (Eds.), La movilidad social en la sociedad industrial (pp. 317-334). Buenos Aires: EUDEBA.

Giménez, G. (2005). “La dotación de capital humano de América Latina y el Caribe”. Revista de La CEPAL.

Herrera, S. (2010). "La importancia de la educación en el desarrollo: la teoría del capital humano y el perfil edad - Ingresos por nivel educativo en Viedma y Carmen de Patagones, Argentina". Revista Pilquen, 12(13), 1-9.

Hussmanns, R. (2004). Defining and measuring informal employment, 21.

Lipset, S. M., y Bendix, R. (1963). La movilidad social en la sociedad industrial. Buenos Aires: EUDEBA.

Lustig, N., Lopez-Calva, L. F., y Ortiz-Juarez, E. (2011). The Decline in Inequality in Latin America: How Much, Since When and Why. Tulane economics working paper series.

Lustig, N., Lopez-Calva, L. F., y Ortiz-Juarez, E. (2013). Deconstucting the decline in inequality in Latin America. Policy Research Working Paper.

Maurizio, R. (2001). "Demanda de trabajo, sobreeducación y distribución del ingreso". In $V$ Congreso Nacional de Estudios del Trabajo. Buenos Aires.

Mincer, J. (1975). "Education, experience and the distribution of earnings and employment: an overview". En F. T. Juster (Ed.), Education, income and human behavior (Vol. I, pp. 71-94). National Bureau of Economic Research.

Neira, I. (2007). "Capital Humano y Desarrollo Económico Mundial: Modelos Econométricos y Perspectivas". Estudios Económicos de Desarrollo Internacional, 7.

Ocampo, J. A. (2001). "Raúl Prebisch y la agenda del desarrollo en los albores del siglo XXI". Revista de La CEPAL, December 2(75), 25-40.

Paz, J. A. (2007). Retornos laborales a la educación en la Argentina. Evolución y estructura actual (Documentos de Trabajo No. 355). Buenos Aires.

Pinto, A. (1968). "Naturaleza e implicaciones de la "Heterogeneidad Estructural" de la America Latina”. El Trimestre Económico, 83-100.

PREALC-OIT. (1978). Sector Informal: funcionamiento y políticas. Santiago de Chile.

Prebisch, R. (1949). "El desarrollo económico de la América Latina y algunos de sus principales problemas". CEPAL - Naciones Unidas, 63.

Prebisch, R. (1970). Transformación y desarrollo: la gran tarea de América Latina. México: Fondo de Cultura Económica.

Rodríguez, O. (2001). "Prebisch: Actualidad de sus ideas básicas". Revista de La CEPAL, (75), 41-52.

Salvia, A. (2012). La trampa neoliberal. Un estudio sobre los cambios en la heterogeneidad estructural y la distribución del ingreso en Argentina: 1990-2003. Buenos Aires: EUDEBA. 
Salvia, A., Comas, G., Gutiérrez Ageitos, P., Quartulli, D., y Stefani, F. (2008). “Cambios en la estructura social del trabajo bajo los regímenes de convertibilidad y postdevalución. Una mirada desde la perspectiva de la heterogeneidad estructural". En J. Lindenboim (Ed.), Trabajo, Ingresos y Políticas públicas en Argentina. Contribuciones para pensar el siglo XXI (pp. 115-159). Buenos Aires: EUDEBA.

Salvia, A., y Donza, E. (1999). "Problemas de medición y sesgos de estimación derivados de la no respuesta completa a las preguntas de ingresos en la EPH (1990-1998)". Asociación Argentina de Especialistas de Estudios Del Trabajo, (18), 93-120.

Salvia, A., y Vera, J. (2013). "Heterogeneidad estructural y distribución de los ingresos familiares en el Gran Buenos Aires (1992-2010)". Desarrollo Económico, 52(208), 427-462.

Salvia, A., y Vera, J. (2015). "Las desigualdades estructurales y el efecto de la educación sobre el empleo pleno". En J. Lindenboim y A. Salvia (Eds.), Hora de balance. Proceso de acumulación, mercado de trabajo y bienestar. Argentina, 2002-2014. Buenos Aires: EUDEBA.

Salvia, A., Vera, J., y Poy, S. (2015). "Cambios y continuidades en la estructura ocupacional urbana argentina”. En J. Lindenboim y A. Salvia (Eds.), Hora de Balance (pp. 133-172). Buenos Aires: EUDEBA.

Schultz, T. W. (1961). "Investment in Human Capital". The American Economic Review, $51(1), 1-17$.

Tokman, V. (1978). "Las relaciones entre los sectores formal e informal". Revista de La CE$P A L,(5), 103-141$.

Trujillo, L., y Villafañe, S. (2011). "Dinámica distributiva y Políticas Públicas: dos décadas de contrastes en la Argentina contemporánea". In M. Novick y S. Villafañe (Eds.), Distribución del Ingreso. Enfoques y políticas públicas desde el sur. Buenos Aires: PNUD; Ministerio de Trabajo, Empleo y Seguridad Social. 